\title{
Deriving surface soil moisture from reflected GNSS signal observations from a grassland site in southwestern France
}

\author{
Sibo Zhang ${ }^{1,2}$, Jean-Christophe Calvet ${ }^{1}$, José Darrozes ${ }^{3}$, Nicolas Roussel ${ }^{3}$, Frédéric Frappart ${ }^{3,4}$, and Gilles Bouhours ${ }^{1}$ \\ ${ }^{1}$ CNRM, UMR3589 (Meteo-France, CNRS), Toulouse, France \\ ${ }^{2}$ Fondation STAE, Toulouse, France \\ ${ }^{3}$ GET, UMR5563 (CNRS, Université Paul Sabatier, UR254 IRD), Toulouse, France \\ ${ }^{4}$ LEGOS, UMR5566 (CNES, CNRS, IRD, UPS), Toulouse, France
}

Correspondence: Jean-Christophe Calvet (jean-christophe.calvet@meteo.fr)

Received: 3 October 2017 - Discussion started: 2 November 2017

Revised: 6 February 2018 - Accepted: 19 February 2018 - Published: 20 March 2018

\begin{abstract}
This work assesses the estimation of surface volumetric soil moisture (VSM) using the global navigation satellite system interferometric reflectometry (GNSS-IR) technique. Year-round observations were acquired from a grassland site in southwestern France using an antenna consecutively placed at two contrasting heights above the ground surface (3.3 and $29.4 \mathrm{~m}$ ). The VSM retrievals are compared with two independent reference datasets: in situ observations of soil moisture, and numerical simulations of soil moisture and vegetation biomass from the ISBA (Interactions between Soil, Biosphere and Atmosphere) land surface model. Scaled VSM estimates can be retrieved throughout the year removing vegetation effects by the separation of growth and senescence periods and by the filtering of the GNSS-IR observations that are most affected by vegetation. Antenna height has no significant impact on the quality of VSM estimates. Comparisons between the VSM GNSS-IR retrievals and the in situ VSM observations at a depth of $5 \mathrm{~cm}$ show good agreement $\left(R^{2}=0.86\right.$ and $\left.\mathrm{RMSE}=0.04 \mathrm{~m}^{3} \mathrm{~m}^{-3}\right)$. It is shown that the signal is sensitive to the grass litter water content and that this effect triggers differences between VSM retrievals and in situ VSM observations at depths of 1 and $5 \mathrm{~cm}$, especially during light rainfall events.
\end{abstract}

\section{Introduction}

Soil moisture is a key component in the hydrological cycle and in the soil-plant-atmosphere continuum. It is also important for irrigation management and flood prediction
(Rodriguez-Iturbe and Porporato, 2007). However, in situ observations of soil moisture are very sparse and with small sampling volumes. On the other hand, L-band satellitederived products, for example, from the Soil Moisture Active Passive (SMAP) mission or the Soil Moisture and Ocean Salinity (SMOS) mission, have a coarse resolution of tens of kilometers (Chan et al., 2016; Kerr et al., 2001). These products consist of surface volumetric soil moisture (VSM) and concern the top soil layer (from the soil surface to a depth of 1 to $5 \mathrm{~cm}$ ). There is a need to monitor VSM at the local scale in order to validate model simulations, and satellite-derived products. The International Soil Moisture Network (Dorigo et al., 2013) has been collecting such in situ observations. The Committee on Earth Observation Satellites (CEOS) Land Product Validation group has recommended expanding the soil moisture networks (Morisette et al., 2006). In particular, the development of new automatic monitoring techniques to measure VSM is needed.

The global navigation satellite system interferometric reflectometry (GNSS-IR) technique has demonstrated strong potential to monitor VSM using ground-based receivers (Chew et al., 2014). GNSS antennas measure the signal directly emitted by the GNSS satellites, together with the signal reflected by the surface surrounding the antenna. The GNSS-IR technique allows relating the reflected signal to the characteristics of the reflecting surface and to retrieve geophysical variables. Over land, variables such as soil moisture, snow depth and vegetation parameters can be observed using this technique (Larson et al., 2008; Small et al., 2010; Larson and Nievinski, 2013; Wan et al., 2015; Larson, 2016; Rous- 
sel et al., 2016; Zhang et al., 2017). GNSS satellites emit active L-band microwave signals (between 1.2 and $1.6 \mathrm{GHz}$ ). The L-band signal is less affected by vegetation effects than shorter wavelengths, which is an asset for retrieving surface soil moisture (Kerr et al., 2001). The GNSS-IR footprint can cover up to thousands of square meters, depending on the antenna height and on the satellite elevation angle (Larson et al., 2010; Vey et al., 2016).

In addition to an antenna specially designed to receive the reflected GNSS signal from the land surface (Zavorotny et al., 2014), classical geodetic-quality GNSS antennas can be used to estimate VSM (Larson et al., 2008). Such antennas have an antenna gain pattern optimized for right hand circular polarization (RHCP) and minimized for left hand circular polarization (LHCP). A GNSS network called Plate Boundary Observatory (PBO) $\mathrm{H}_{2} \mathrm{O}$ with geodetic-quality on-ground antennas in western USA is currently used to monitor VSM (Larson et al., 2013; Larson, 2016; Chew et al., 2016) and snow depth (Larson et al., 2009). The basic observation used in this technique is the signal-to-noise ratio (SNR) which is related to temporal changes in the interference between the direct and the reflected GNSS signals. Each GPS satellite repeats the same orbital cycle from one day to another (offset of a few tenths of meter between two adjacent cycles). This property permits monitoring surface changes through time of the environmental conditions surrounding the receiving antenna.

The present-day Block II R-M (Replenishment Modernized) and Block II F (Follow-on) GPS satellites now transmit a L2C $(1227.60 \mathrm{~Hz})$ civilian signal. Power and precision of the L2C signal are higher than for the L1 C/A signal $(1575.42 \mathrm{~Hz})$ transmitted by all GPS satellites. Several previous studies, such as Larson et al. (2008, 2010), Chew et al. (2014), Chew et al. (2016) and Small et al. (2016) exclusively analyzed the SNR data from the GPS L2C signal to retrieve soil moisture. The Block II F satellites also transmit the latest L5 signal $(1176.45 \mathrm{~Hz})$ as well, which features even higher power, greater bandwidth and an advanced signal design. There are now seven Block II R-M satellites (pseudorandom noise, PRN, numbers 5, 7, 12, 15, 17, 29 and 31, identifying each satellite) and 12 Block II F satellites (PRN $1,3,6,8,9,10,24,25,26,27,30$ and 32).

Due to the motion of the satellites, the direct and reflected signals cause an interference pattern in SNR data. The SNR oscillations depend on known attributes such as the satellite elevation angle, signal wavelength and antenna height. The SNR amplitude and phase can be solved by using the least squares estimation (LSE) method (Larson et al., 2008; Chew et al., 2016). Larson et al. (2008, 2010) empirically showed that phase correlates with near-surface soil moisture, with values of the coefficient of determination $\left(R^{2}\right)$ ranging from 0.76 to 0.90 . This property was used by Chew et al. (2014) to develop an algorithm to estimate surface soil moisture (top $5 \mathrm{~cm}$ ) for bare soil. They used a physical surface scattering and dielectric permittivity model to derive a relationship between the phase and soil moisture, in volumetric units $\left(\mathrm{m}^{3} \mathrm{~m}^{-3}\right)$. Vey et al. (2016) validated this algorithm, using field observations acquired during the 20082014 period from a site presenting a high percentage of bare soil. They obtained the following $R^{2}$ and root mean square error (RMSE) scores for VSM retrievals: $R^{2}=0.80$ and RMSE $=0.05 \mathrm{~m}^{3} \mathrm{~m}^{-3}$. However, for vegetated soil the phase of the SNR is also affected by vegetation. Chew et al. (2016) showed that seasonal vegetation effects on phase have to be considered for soil moisture estimation. They also observed that amplitude decreased as vegetation grew. A model database for the SNR from L2C signal was used to remove most significant vegetation effects. Small et al. (2016) compared different algorithms of GNSS-IR soil moisture retrieval in the presence of vegetation.

Zhang et al. (2017) used the GNSS-IR technique for a wheat field throughout the growth and senescence period in 2015. The L1 C/A signal was acquired over a wheat field during a period of about 7 months using a Leica GR25 receiver and a Leica AR10 antenna at a constant height of $2.5 \mathrm{~m}$ above the soil surface. They showed that VSM could not be retrieved when the vegetation canopy is too dense, i.e., plant height and simulated dry aboveground biomass larger than one wavelength ( $\sim 19 \mathrm{~cm}$ for L1) and $0.08 \mathrm{~kg} \mathrm{~m}^{-2}$, respectively. On the other hand, relative plant height could be retrieved in such conditions. In this study, both L2C and L5 signals were acquired over a meadow during a rather long period of time of about 15 months using the same equipment (GR25 receiver, AR10 antenna) at contrasting heights (3.3 and $29.4 \mathrm{~m}$ ) above the soil surface.

The objectives of this study are to (1) investigate VSM estimation over a meadow, contrasting conditions of plant phenology (growth, senescence, after and before cutting), (2) compare the use of L2C and L5 signals (3) assess the impact of a major change in the height of the receiving antenna above the soil surface, in relation to the SNR sampling interval. Investigating the impact of the sampling interval on VSM retrievals is needed due to the fact that small sampling intervals (e.g., $1 \mathrm{~s}$ ) generate a large amount of data ( $\sim 100 \mathrm{Mb} \mathrm{day}^{-1}$ for GPS satellites). Larger sampling intervals may be defined to reduce the amount of daily data.

A key difference between this study and Zhang et al. (2017) is related to the type of observed vegetation canopy. The meadow considered in this study and the wheat field considered by Zhang et al. (2017) present contrasting characteristics. The meadow is cut once a year and consists of a multi-species permanent grassland incorporating a litter composed of dead leaves. On the other hand, the wheat crop in Zhang et al. (2017) consisted of a single plant species with no litter.

Past microwave remote sensing studies (e.g., Saleh et al., 2007) have shown that permanent grasslands behave differently from crops. Because permanent grasslands incorporate a litter composed of dead leaves, they can intercept precipitation considerably more than annual crops. The short growing 
cycle of annual crops does not allow for the accumulation of large amounts of litter material. This property of permanent grasslands can have a major effect on the microwave signal and can perturb the retrieval of VSM, even at GPS L-band (Saleh et al., 2007). Also, the structure of grass canopies differs from the structure of crops such as wheat and this has an impact on the attenuation of the microwave signal by vegetation (Wigneron et al., 2002).

GPS SNR data from both L2C and L5 signals are obtained using a geodetic-quality GNSS antenna. SNR analysis using the GNSS-IR technique is used to retrieve VSM over a field covered with grass using the normalization method based on the newly established scaled wetness index proposed by Zhang et al. (2017). Another point to underline is the impact of the antenna height (here two levels: 3.3 and $29.4 \mathrm{~m}$ above the soil surface) on the VSM retrieval. Moreover, the VSM retrievals from two kinds of GPS signal wavelengths (24.45 and $25.40 \mathrm{~cm}$ for L2C and L5, respectively) are compared with field observations. We analyze the vegetation effects on VSM retrieval accuracy. Another important topic addressed is the influence of the sampling interval on the VSM estimates. As the SNR period changes depending on the antenna height, satellite elevation angle, elevation angle change rate and GNSS signal wavelength, the sampling interval has to be adjusted accordingly in order to maintain the VSM retrieval accuracy.

Data are described in Sect. 2 and methods in Sect. 3. The obtained soil moisture retrievals are presented in Sect. 4 and compared with independent VSM estimates. Results are discussed in Sect. 5, and the main conclusions are summarized together with prospects for further research in Sect. 6.

\section{Site and data}

\subsection{Site description and validation data}

The study site is located at the premises of Meteo-France in Toulouse, France, over an experimental field covered with grass $\left(43^{\circ} 34^{\prime} 26^{\prime \prime} \mathrm{N}, 1^{\circ} 22^{\prime} 27^{\prime \prime} \mathrm{E}\right)$. Since 2012 , this instrumented site has included soil moisture profile observations from the surface down to a depth of $2.2 \mathrm{~m}$. Other measurements such as turbulent fluxes are made in the framework of the Meteopole-Flux project (https://www.umr-cnrm.fr/spip. php?article874\&lang=en) and ICOS (Integrated Carbon Observation System, https://icos-eco.fr/). The fine-earth soil in the experimental field at a depth of $5 \mathrm{~cm}$ consists of $51 \%$ sand, $14.5 \%$ clay and $34.5 \%$ silt.

The grass height did not exceed $0.3 \mathrm{~m}$ during the experiment time period. This is much lower than maximum height of the wheat crop $(\sim 1 \mathrm{~m})$ in Zhang et al. (2017). A large difference could also be noticed in maximum aboveground dry biomass values: less than $0.5 \mathrm{~kg} \mathrm{~m}^{-2}$ for grass (this study) and about $1 \mathrm{~kg} \mathrm{~m}^{-2}$ for wheat (Zhang et al., 2017). The grass was cut twice during the study period. The cutting process took several days and the grass was fully cut on 7 October 2015 and 9 July 2016, for the 29.4 and $3.3 \mathrm{~m}$ antenna observing areas, respectively.

Mean in situ VSM observations at 5 and $1 \mathrm{~cm}$ depths were performed using precise Delta-T ML2x ThetaProbes and low-cost Decagon EC-5 VSM sensors, respectively. Three ThetaProbes measured VSM at a depth of $5 \mathrm{~cm}$ and were located within a few meters of each other (red star in Fig. 1). The mean value was derived from these probes to represent the in situ VSM observations at $5 \mathrm{~cm}$. Only one EC-5 sensor was used to measure VSM at $1 \mathrm{~cm}$. Precipitation measurements were made in the experimental field by one rain gauge close to the in situ soil moisture sensors. A small fraction of the precipitation time series was missing. Missing data were replaced by the precipitation data obtained from the SAFRAN atmospheric analysis (Durand et al., 1993, 1999). Additionally, scaled VSM observations at a depth of $1 \mathrm{~cm}$ and scaled VSM simulations for the top $1 \mathrm{~cm}$ thick soil layer were used as independent benchmarks for validation.

VSM simulations for the top $1 \mathrm{~cm}$ were produced using the ISBA (Interactions between Soil, Biosphere, and Atmosphere) land surface model within the SURFEX (version 8.0) modeling platform (Masson et al., 2013). In addition to VSM, simulations included the soil iced water content and the vegetation aboveground dry biomass. The ISBA model used the atmospheric forcing data produced by the SAFRAN atmospheric analysis of Météo-France. The model version used in this study was designed for generic country-scale simulations over France at a spatial resolution of $8 \mathrm{~km} \times 8 \mathrm{~km}$. It was not calibrated for this particular site. Sub-grid vegetation types are represented and soil moisture and soil temperature profiles are simulated for each vegetation type, independently of other vegetation types. In this study, the $\mathrm{C} 3$ grassland plant functioning type and a multilayer representation of the soil hydrology are considered. The model soil depth is $12 \mathrm{~m}$, with 15 layers, and the layer thickness increases from the top surface layer to the deepest layers (Decharme et al., 2011). It must be noted that the SAFRAN precipitation forcing is based on ground observations and is quite realistic (Quintana-Segui et al., 2008). The ISBA configuration and the SAFRAN atmospheric analysis used to force the model are described in Lafont et al. (2012).

\subsection{GNSS data}

In this study, GNSS SNR data were acquired using a Leica GR25 multi-constellation and multi-band geodetic receiver equipped with an AR10 antenna for more than 1 year. Two measurement configurations were explored (Fig. 1). First, from 1 August 2015 to 5 June 2016, the antenna was placed at the top of a building close to the studied grassland, at a height of $29.4 \mathrm{~m}$ above the soil surface $\left(43^{\circ} 34^{\prime} 30^{\prime \prime} \mathrm{N}, 1^{\circ} 22^{\prime} 26^{\prime \prime} \mathrm{E}\right)$. Second, from 8 June to 6 October 2016, the antenna was moved on top of a small technical shed located within the meadow, close to the in situ sensors, at a height of $3.3 \mathrm{~m}$ 


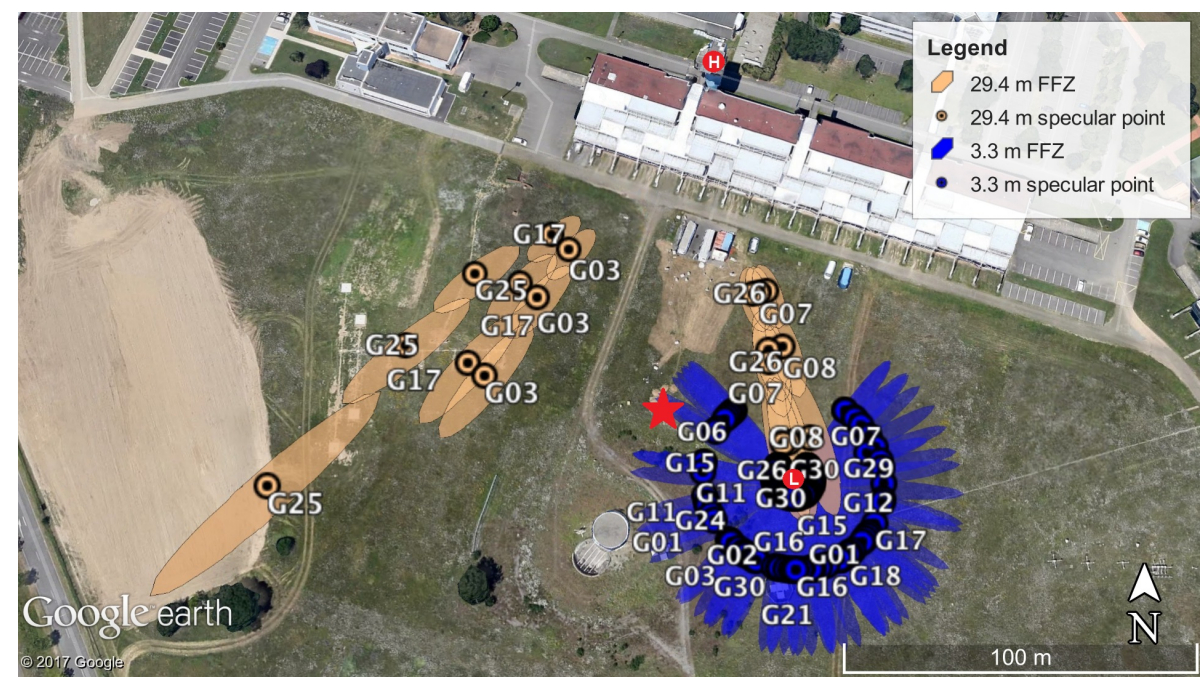

Figure 1. Experimental site of Meteopole-Flux. The specular reflection points and first Fresnel zone (FFZ) areas from the selected satellite tracks are shown in orange for a $29.4 \mathrm{~m}$ GNSS antenna ("H" red dot). The specular reflection points and FFZ areas for a $3.3 \mathrm{~m}$ GNSS antenna ("L" red dot) are shown in blue. The red star indicates the location of in situ soil moisture observations. Background geographic information is from Google Earth.

above the soil surface. During the first $29.4 \mathrm{~m}$ antenna height experiment, the SNR sampling interval was reduced from 10 to $1 \mathrm{~s}$ on 19 March. When the antenna height was changed from 29.4 to $3.3 \mathrm{~m}$, the sampling interval remained at a value of $1 \mathrm{~s}$. GNSS SNR data were missing for 24 days: from 1 to 11 January, from 17 to 26 May and on 1, 6 and 7 June 2016.

In this study, both L2C and L5 SNR data from the GPS Block II R-M and Block II F satellites were used. The ascending and descending parts of the same satellite were processed separately and were considered as independent satellite tracks (Roussel et al., 2015, 2016).

The valid SNR segment for each ascending or descending satellite track was limited based on the available satellite elevation angle range ( $90^{\circ}$ being defined as zenith). For the $3.3 \mathrm{~m}$ antenna height, the multipath signature was small at elevation angles above $30^{\circ}$ or below $7^{\circ}$, and the reflecting region (first Fresnel zone, FFZ) often included both ground and surrounding obstructions. Therefore, only data corresponding to elevation angles ranging from 7 to $30^{\circ}$ were considered. For a given satellite track, the field observation area was about $300 \mathrm{~m}^{2}$, and the observing duration was about $1 \mathrm{~h}$ (Table 1). The range of instantaneous FFZ areas is indicated in Table 1. After sorting elevation angles, 36 and 21 satellite tracks were available for L2C and L5 SNR data, respectively. The corresponding reflecting points and FFZ areas, obtained using a reflection location model for GNSS-R (Roussel et al., 2014), are shown in Fig. 1. The successive experimental configurations are listed in Table 2 and shown in Fig. 2.

Measurements from the antenna at a height of $29.4 \mathrm{~m}$ were affected by surrounding obstructions (buildings and impervious areas like car park, roads, etc.) and by an under-sampling issue at a sampling interval of $10 \mathrm{~s}$ (see Sect. 4.2). In order to cope with these problems, only six satellite tracks were used to retrieve VSM from L2C SNR data (GPS PRN 03, 07, 08, 17, 25 and 26), and four satellites tracks from L5 SNR data (GPS PRN 03, 08, 25 and 26). Satellite track characteristics and instantaneous FFZ areas are given in Table 1. The selection of satellite tracks and elevation angles was performed by comparing VSM retrievals with the in situ VSM observations described in Sect. 2.1. It must be noted that this limitation only affected measurements at a height of $29.4 \mathrm{~m}$ and was caused by the more complex experimental constraints in this configuration (e.g., possible parasitic signal reflection on buildings). For the low antenna configuration $(3.3 \mathrm{~m})$, this additional data sorting was not needed and all available satellite tracks with a complete elevation angle range (between 7 and $30^{\circ}$ ) were used. As a result, a larger variety of satellite tracks could be used for the antenna at a height of $3.3 \mathrm{~m}$ with $1 \mathrm{~s}$ sampling. With a higher antenna, the size of the observed reflecting surface markedly increases (Larson et al., 2010). Although the elevation angle range used for the antenna at $29.4 \mathrm{~m}$ is smaller than for the antenna at $3.3 \mathrm{~m}$ (Table 1), a much larger observing area is obtained for each satellite track. More details about the elevation range, the observing time period and approximate observing area for each satellite track are shown in Table 1. The SNR data are typically converted from their native logarithmic units $(\mathrm{dB}-\mathrm{Hz})$ to a linear scale $\left(\mathrm{V} \mathrm{V}^{-1}\right)$ (Vey et al., 2016). For a static receiver, the SNR is governed to a large extent by the interference pattern (IP). The IP is defined as the coherent summation of direct and reflected GNSS signals on the in-phase and quadrature space (Zavorotny et al., 2014). This coherent summation generates an IP where high and intermediate frequencies, distinct from noise frequencies, are related to the difference of trav- 

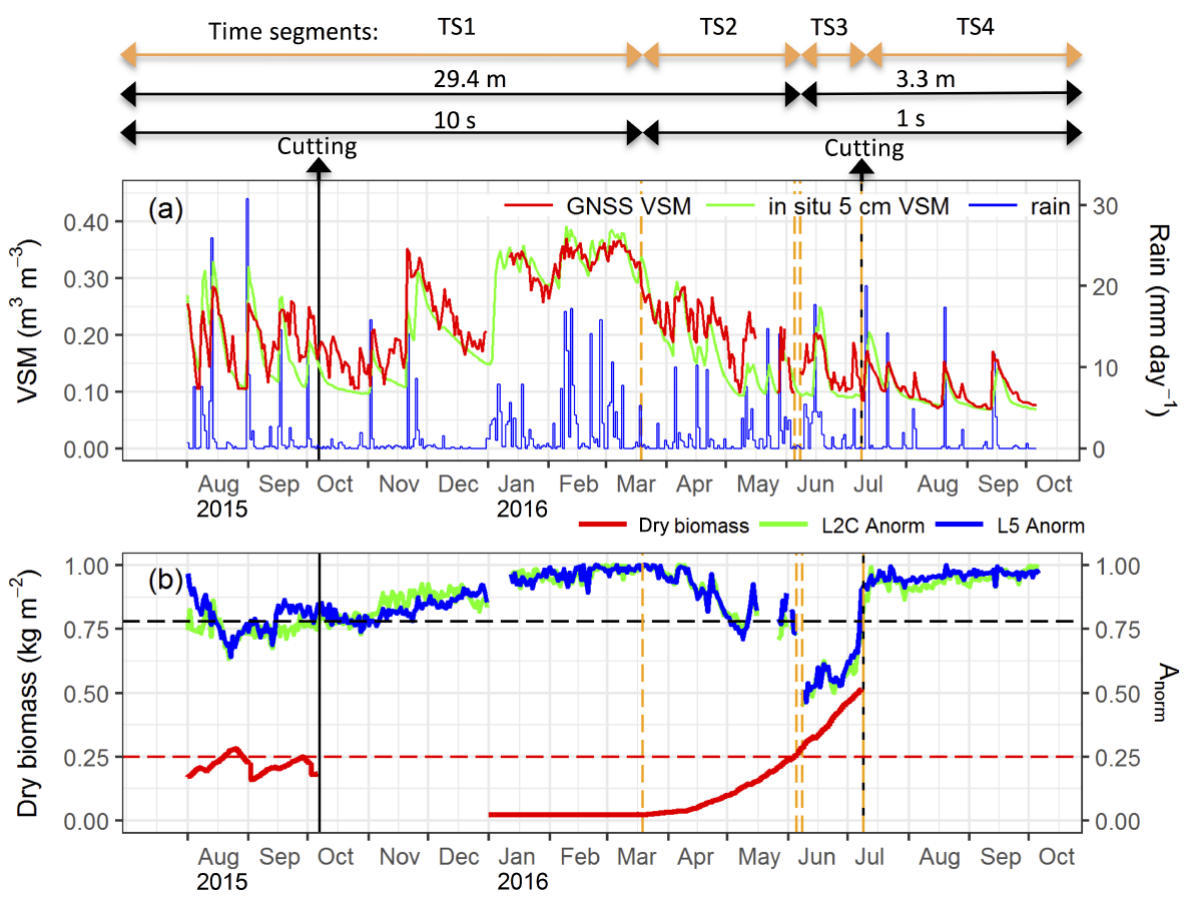

Figure 2. Timeline of experiment. (a) Daily GNSS VSM retrieval time series $(N=409)$ using both L2C and L5 SNR data for the whole experimental period (from 1 August 2015 to 6 October 2016) is shown in red line, together with daily mean in situ VSM observations at a depth of $5 \mathrm{~cm}$ (green line). The blue line represents the daily precipitation in $\mathrm{mm} \mathrm{day}^{-1}$. The black lines indicate the grass cutting before 7 October 2015 and before 9 July 2016. The retrievals are obtained separately depending on four time segments (Table 2). (b) The red line represents the aboveground dry biomass $\left(\mathrm{kg} \mathrm{m}^{-2}\right)$ of the grass simulated by the ISBA model before grass cutting; the red dashed line indicates the maximum simulated dry biomass $\left(0.25 \mathrm{~kg} \mathrm{~m}^{-2}\right)$ in 2015 . Grass cutting is also shown in black solid lines. The L2C (L5) SNR normalized amplitude ( $A_{\text {norm }}$, dimensionless) time series is shown in green (blue). Normalization is performed separately for TS1 and TS2, and for the period with data acquired from the $3.3 \mathrm{~m}$ antenna using a $1 \mathrm{~s}$ sampling interval. The latter corresponds to the merged TS3 and TS4. The black dashed line indicates the $A_{\text {norm }}$ threshold (0.78) for evaluating the vegetation effects.

Table 1. Characteristics of the selected satellite tracks from the GNSS antenna at a $29.4 \mathrm{~m}$ height and at a $3.3 \mathrm{~m}$ height (north is $0^{\circ}$ azimuth angle, clockwise rotation).

\begin{tabular}{|c|c|c|c|c|c|c|}
\hline $\begin{array}{l}\text { Antenna } \\
\text { height } \\
\text { (m) }\end{array}$ & $\begin{array}{l}\text { Satellite } \\
\text { tracks }\end{array}$ & $\begin{array}{r}\text { Elevation angle } \\
\text { range }\left({ }^{\circ}\right)\end{array}$ & $\begin{array}{r}\text { Azimuth angle } \\
\text { range }\left({ }^{\circ}\right)\end{array}$ & $\begin{array}{l}\text { Areas per } \\
\text { track }\left(\mathrm{m}^{2}\right)\end{array}$ & $\begin{array}{r}\text { Instantaneous FFZ } \\
\text { area range }\left(\mathrm{m}^{2}\right)\end{array}$ & $\begin{array}{r}\text { Time duration per } \\
\text { track (min) }\end{array}$ \\
\hline \multirow[t]{6}{*}{29.4} & GPS PRN 03 & 14 to 23 & 216 to 219 & $\sim 900$ & $\sim 400-150$ & 21.6 \\
\hline & GPS PRN 07 & & 168 to 169 & & & 21.2 \\
\hline & GPS PRN 08 & & 166 to 169 & & & 20.3 \\
\hline & GPS PRN 17 & & 223 to 228 & & & 24.0 \\
\hline & GPS PRN 26 & & 168 to 171 & & & 20.3 \\
\hline & GPS PRN 25 & 9 to 17 & 228 to 232 & $\sim 2000$ & $\sim 1000-300$ & 20.7 \\
\hline 3.3 & $\begin{array}{l}36 \text { for L2C } \\
\text { (10 during TS3) } \\
21 \text { for L5 } \\
\text { (6 during TS3) }\end{array}$ & 7 to 30 & - & $\sim 300$ & $\sim 200-10$ & $\sim 60$ \\
\hline
\end{tabular}

eled distance between direct and reflected waves. The IP can be characterized with GNSS receivers using either two antennas (e.g., Rodriguez-Alvarez et al., 2011) or one antenna (e.g., Larson et al., 2008; Chew et al., 2014; Zhang et al.,
2017). In this study we used the one-antenna IP technique as illustrated by Fig. 1 in Larson et al. (2016) for a simple planar and horizontal ground reflection. A low order polyno- 
Table 2. Soil moisture scores for four time segments from the comparison between scaled VSM validation data (in situ VSM observations at 1 and $5 \mathrm{~cm}$ and ISBA VSM simulations at $1 \mathrm{~cm}$ ) and scaled GNSS VSM retrievals (both L2C and L5). Scores in $\mathrm{m}^{3} \mathrm{~m}^{-3}$ are given (between brackets) for in situ observations at $-5 \mathrm{~cm}$. MAE is the mean absolute error, RMSE is the root mean square error and SDD is the standard deviation of difference. $N$ is the number of observations.

\begin{tabular}{|c|c|c|c|c|c|c|c|c|c|c|c|c|}
\hline Time segment & \multicolumn{3}{|c|}{ TS1 } & \multicolumn{3}{|c|}{ TS2 } & \multicolumn{3}{|c|}{ TS3 } & \multicolumn{3}{|c|}{ TS4 } \\
\hline Dates & \multicolumn{3}{|c|}{$\begin{array}{l}\text { from } 1 \text { August } 2015 \\
\text { to } 18 \text { March } 2016\end{array}$} & \multicolumn{3}{|c|}{$\begin{array}{l}\text { from } 19 \text { March } 2016 \\
\quad \text { to } 5 \text { June } 2016\end{array}$} & \multicolumn{3}{|c|}{$\begin{array}{l}\text { from } 8 \text { June } 2016 \\
\text { to } 8 \text { July } 2016\end{array}$} & \multicolumn{3}{|c|}{$\begin{array}{l}\text { from } 9 \text { July } 2016 \\
\text { to } 6 \text { October } 2016\end{array}$} \\
\hline Vegetation stages & \multicolumn{3}{|c|}{$\begin{array}{l}\text { senescence, cutting, } \\
\text { dormancy }\end{array}$} & \multicolumn{3}{|c|}{ growing } & \multicolumn{3}{|c|}{ growing } & \multicolumn{3}{|c|}{ cutting } \\
\hline $\begin{array}{l}\text { Antenna height } \\
\text { (m) }\end{array}$ & \multicolumn{3}{|c|}{29.4} & \multicolumn{3}{|c|}{29.4} & \multicolumn{3}{|c|}{3.3} & \multicolumn{3}{|c|}{3.3} \\
\hline $\begin{array}{l}\text { Sampling interval } \\
\text { (s) }\end{array}$ & \multicolumn{3}{|c|}{10} & \multicolumn{3}{|c|}{1} & \multicolumn{3}{|c|}{1} & \multicolumn{3}{|c|}{1} \\
\hline$N$ & \multicolumn{3}{|c|}{220} & \multicolumn{3}{|c|}{68} & \multicolumn{3}{|c|}{31} & \multicolumn{3}{|c|}{90} \\
\hline $\begin{array}{l}\text { Independent soil } \\
\text { moisture } \\
\text { estimates }\end{array}$ & $\begin{array}{l}\text { ISBA } \\
1 \mathrm{~cm}\end{array}$ & $\begin{array}{l}\text { in situ } \\
1 \mathrm{~cm}\end{array}$ & $\begin{array}{l}\text { in situ } \\
5 \mathrm{~cm}\end{array}$ & $\begin{array}{l}\text { ISBA } \\
1 \mathrm{~cm}\end{array}$ & $\begin{array}{l}\text { in situ } \\
1 \mathrm{~cm}\end{array}$ & $\begin{array}{l}\text { in situ } \\
5 \mathrm{~cm}\end{array}$ & $\begin{array}{l}\text { ISBA } \\
1 \mathrm{~cm}\end{array}$ & $\begin{array}{l}\text { in situ } \\
1 \mathrm{~cm}\end{array}$ & $\begin{array}{l}\text { in situ } \\
5 \mathrm{~cm}\end{array}$ & $\begin{array}{l}\text { ISBA } \\
1 \mathrm{~cm}\end{array}$ & $\begin{array}{l}\text { in situ } \\
1 \mathrm{~cm}\end{array}$ & $\begin{array}{l}\text { in situ } \\
5 \mathrm{~cm}\end{array}$ \\
\hline MAE & 0.32 & 0.33 & $\begin{array}{l}0.30 \\
(0.031 \\
\left.\mathrm{m}^{3} \mathrm{~m}^{-3}\right)\end{array}$ & 0.47 & 0.58 & $\begin{array}{l}0.56 \\
(0.039 \\
\left.\mathrm{m}^{3} \mathrm{~m}^{-3}\right)\end{array}$ & 0.34 & 0.54 & $\begin{array}{l}0.65 \\
(0.035 \\
\left.\mathrm{m}^{3} \mathrm{~m}^{-3}\right)\end{array}$ & 0.33 & 0.33 & $\begin{array}{l}0.38 \\
(0.013 \\
\left.\mathrm{m}^{3} \mathrm{~m}^{-3}\right)\end{array}$ \\
\hline RMSE & 0.40 & 0.42 & $\begin{array}{l}0.40 \\
(0.040 \\
\left.\mathrm{m}^{3} \mathrm{~m}^{-3}\right)\end{array}$ & 0.61 & 0.71 & $\begin{array}{l}0.65 \\
(0.048 \\
\left.\mathrm{m}^{3} \mathrm{~m}^{-3}\right)\end{array}$ & 0.51 & 0.69 & $\begin{array}{l}0.80 \\
(0.043 \\
\left.\mathrm{m}^{3} \mathrm{~m}^{-3}\right)\end{array}$ & 0.42 & 0.44 & $\begin{array}{l}0.62 \\
(0.019 \\
\left.\mathrm{m}^{3} \mathrm{~m}^{-3}\right)\end{array}$ \\
\hline SDD & 0.40 & 0.42 & $\begin{array}{l}0.40 \\
(0.037 \\
\left.\mathrm{m}^{3} \mathrm{~m}^{-3}\right)\end{array}$ & 0.61 & 0.71 & $\begin{array}{l}0.65 \\
(0.039 \\
\left.\mathrm{m}^{3} \mathrm{~m}^{-3}\right)\end{array}$ & 0.51 & 0.69 & $\begin{array}{l}0.80 \\
(0.036 \\
\left.\mathrm{m}^{3} \mathrm{~m}^{-3}\right)\end{array}$ & 0.42 & 0.44 & $\begin{array}{l}0.62 \\
(0.018 \\
\left.\mathrm{m}^{3} \mathrm{~m}^{-3}\right)\end{array}$ \\
\hline$R^{2}$ & 0.84 & 0.83 & 0.85 & 0.66 & 0.55 & 0.62 & 0.75 & 0.57 & 0.45 & 0.83 & 0.81 & 0.65 \\
\hline
\end{tabular}

mial curve is fitted to SNR data in order to retain only the multipath IP (Bilich et al., 2008).

\section{Methods}

The modulation of the SNR by the multipath frequency can be expressed as (Larson et al., 2008, 2010; Chew et al., 2016):

$\mathrm{SNR}=A \cos \left(\frac{4 \pi H_{0}}{\lambda} \sin \theta-\phi\right)$,

where $A$ is the amplitude of the modulation, $\phi$ is the phase offset, $\theta$ is the satellite elevation angle and $\lambda$ is the GNSS signal wavelength. $H_{0}$ is a fixed a priori effective antenna height for each satellite track, which is not known and has to be estimated from the SNR data in snow-free and sparse vegetation conditions (Chew et al., 2016). Based on Eq. (1), SNR phase $(\phi)$ can be solved by LSE method, and then this estimated $\phi$ can be used to retrieve VSM.

Due to the good linear relationship between $\phi$ and in situ surface VSM, VSM can be estimated for each satellite track (Chew et al., 2016):

$\mathrm{VSM}=S \cdot\left(\phi-\phi_{\min }\right)+\mathrm{VSM}_{\text {resid }}$

The $S$ parameter (in $\mathrm{m}^{3} \mathrm{~m}^{-3}$ degree ${ }^{-1}$ ) is defined using the a priori value. A value of $S=0.0148 \mathrm{~m}^{3} \mathrm{~m}^{-3}$ degree $^{-1}$ was proposed by Chew et al. (2016) for the $\mathrm{PBO} \mathrm{H}_{2} \mathrm{O}$ network. This value is adapted to situations of low vegetation density or cover and is valid for the Trimble antennas used in the $\mathrm{PBO} \mathrm{H}_{2} \mathrm{O}$ network. In this equation, the $\phi$ time series is zeroed using a minimum phase value $\left(\phi_{\min }\right)$ for each satellite track. This procedure is useful for ensuring compatibility among different satellite tracks. $\phi_{\min }$ is the mean of the lowest $15 \%$ of $\phi$ values for each satellite track during the considered time segment and $\mathrm{VSM}_{\text {resid }}$ is the residual (minimum) volumetric soil moisture value.

\subsection{A new normalized SNR phase method (Zhang et al., 2017)}

In this study, the method proposed by Zhang et al. (2017) is used. Normalizing $\phi$ time series ensures compatibility among different satellite tracks (Zhang et al., 2017). Here, $\phi$ is normalized with zero minimum in order to obtain the scaled wetness index $\left(\phi_{\text {index }}\right)$ as the following:

$\phi_{\text {index }}=\frac{\phi-\phi_{\min }}{\phi_{\max }-\phi_{\min }}$,

where $\phi_{\min }$ and $\phi_{\max }$ are the mean of the lowest and highest $15 \%$ of the statistical distribution of $\phi$ for each satellite track during the considered time segment (TS), respectively. This averaging procedure is used in order to filter out outliers corresponding to abnormally high or low $\phi$ estimates. Negative $\phi_{\text {index }}$ values are replaced by zero. 
Moreover, $\phi_{\text {index }}$ can be used to estimate VSM as follows:

$$
\begin{aligned}
\mathrm{VSM} & =\phi_{\text {index }} \cdot\left(\mathrm{VSM}_{\mathrm{obs} \_\max }-\mathrm{VSM}_{\mathrm{obs} \_ \text {min }}\right) \\
& +\mathrm{VSM}_{\text {obs_min }} .
\end{aligned}
$$

Similarly to phase computation and in order to avoid artifacts, $\mathrm{VSM}_{\text {obs_min }}$ and $\mathrm{VSM}_{\text {obs_max }}$ are set as the mean of the lowest and highest $15 \%$ of daily mean in situ VSM observations at a depth of $5 \mathrm{~cm}$ during the considered time segment, respectively. The median VSM estimate from all available satellite tracks is considered as the final VSM estimate per day. In order to better correct for vegetation effects, vegetation growth and senescence were considered as independent time segments instead of applying Eqs. (3)-(4) to the whole period.

\subsection{Assessment of vegetation effects}

SNR amplitude $(A)$ is affected by vegetation, which can be used to assess whether or not vegetation effects are significant. Chew et al. (2016) defined the normalized amplitude $\left(A_{\text {norm }}\right)$ as the ratio of amplitude to the average of the top $20 \%$ amplitude values. $A_{\text {norm }}$ (dimensionless) values below 0.78 indicate that vegetation effects are significant and cannot be neglected. When vegetation effects are significant, the $S$ parameter value may depart from the value used in Eq. (2). A way to cope with this issue is to apply the Zhang et al. (2017) method for a given time segment presenting consistent vegetation properties. Phase is scaled and $S$ is not needed. The time series in this study is separated into four time segments: (1) TS1, from 1 August 2015 to 18 March 2016 (a vegetation senescence and dormancy period with data acquired from the antenna at $29.4 \mathrm{~m}$ using a $10 \mathrm{~s}$ sampling interval); (2) TS2, from 19 March to 5 June 2016 (a vegetation growing period with data acquired from the antenna at $29.4 \mathrm{~m}$ using a $1 \mathrm{~s}$ sampling interval); (3) TS3, from 8 June to 8 July 2016 (a vegetation growing period with data acquired from the antenna at $3.3 \mathrm{~m}$ antenna using a $1 \mathrm{~s}$ sampling interval); and (4) TS4, from 9 July to 6 October 2016 (after the grass cutting with data acquired from the antenna at $3.3 \mathrm{~m}$ using a $1 \mathrm{~s}$ sampling interval).

Another step is to select relevant satellite tracks under significant vegetation effects. This is particularly challenging in dense vegetation conditions. Even in conditions presenting significant vegetation effects, some satellite tracks can be selected to retrieve VSM. This occurs during TS3, corresponding to low $A_{\text {norm }}$ values (Fig. 2). In order to select satellite tracks in such conditions, only tracks presenting a continuity of VSM retrievals with the following vegetation senescence period (TS4) are kept. Only tracks giving similar VSM estimates (difference lower than $0.06 \mathrm{~m}^{3} \mathrm{~m}^{-3}$ ) at the end of TS3 and at the beginning of TS4 are used for TS3. This procedure eliminates the tracks corresponding to the most densely vegetated areas in the grass field.

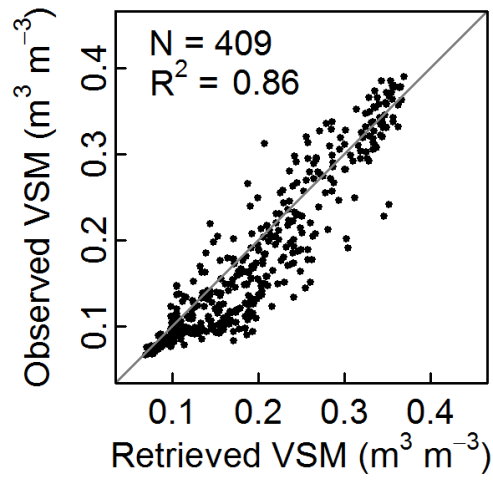

Figure 3. Scatter plot of daily mean in situ VSM observations $(N=409)$ at a depth of $5 \mathrm{~cm}$ vs. GNSS VSM retrievals (from both L2C and L5) for the whole experimental period from 1 August 2015 to 6 October 2016.

\section{Results}

\subsection{VSM estimates}

Figure 2 presents the VSM estimates derived from both the L2C and L5 SNR data using the normalized SNR phase method (see Sect. 3.1) and the vegetation correction method (see Sect. 3.2). Results are shown for the whole experiment period from 1 August 2015 to 6 October 2016, and for all the experimental configurations of antenna height, sampling interval and grass cutting (time segments).

The first grass cutting event occurs during TS1 but has no effect on $A_{\text {norm }}$ because the aboveground biomass is relatively low (less than $0.25 \mathrm{~kg} \mathrm{~m}^{-2}$ ), as shown in Fig. 2. On the other hand, the second cutting occurring before 9 July 2016 has a significant effect on $A_{\text {norm }}$ because, at that time, vegetation is not yet senescent (aboveground biomass is about $0.50 \mathrm{~kg} \mathrm{~m}^{-2}$ ). Another reason to separate TS3 and TS4 is that mean $\mathrm{L} 2 \mathrm{C} A_{\text {norm }}$ values are significantly smaller during TS3 ( 0.56 and 0.94 for TS3 and TS4, respectively).

The scaled wetness indexes $\left(\phi_{\text {index }}\right)$ and VSM estimates are obtained for each of these four time segments. The VSM scores for the four separated time segments are recorded in Table 2. The mean absolute error (MAE), RMSE and $R^{2}$ scores for senescent/dormant and cut vegetation (TS1 and TS4) are better than during the vegetation growing period (TS2 and TS3). Scatter plot of the in situ VSM observations $(N=409)$ at a depth of $5 \mathrm{~cm}$ versus GNSS VSM retrievals is shown for the whole experiment in Fig. 3. The RMSE and the standard deviation of difference (SDD) scores are RMSE $=0.038 \mathrm{~m}^{3} \mathrm{~m}^{-3}$ and $\mathrm{SDD}=0.035 \mathrm{~m}^{3} \mathrm{~m}^{-3}$, respectively. The $R^{2}$ score is equal to 0.86 for merged L2C and L5 SNR data. About the same value is found using only $\mathrm{L} 2 \mathrm{C}$ data $\left(R^{2}=0.85\right)$. The mean bias $\left(0.02 \mathrm{~m}^{3} \mathrm{~m}^{-3}\right)$ is positive, because the VSM estimates are generally larger than in situ VSM observations at $5 \mathrm{~cm}$ depth. 
Table 3. Soil moisture scores between daily mean in situ VSM observations at a depth of $5 \mathrm{~cm}$ and GNSS VSM retrievals (either L2C or L5) during TS1 (SNR data from the $29.4 \mathrm{~m}$ antenna with $10 \mathrm{~s}$ sampling interval from 1 August 2015 to 18 March 2016). MAE, RMSE, SDD and $N$ are defined in Table 2.

\begin{tabular}{lrr}
\hline Signal & L2C & L5 \\
\hline$N$ & 220 & 220 \\
Mean bias $\left(\mathrm{m}^{3} \mathrm{~m}^{-3}\right)$ & 0.016 & 0.017 \\
MAE $\left(\mathrm{m}^{3} \mathrm{~m}^{-3}\right)$ & 0.032 & 0.033 \\
RMSE $\left(\mathrm{m}^{3} \mathrm{~m}^{-3}\right)$ & 0.042 & 0.042 \\
SDD $\left(\mathrm{m}^{3} \mathrm{~m}^{-3}\right)$ & 0.039 & 0.038 \\
$R^{2}$ & 0.83 & 0.84 \\
\hline
\end{tabular}

Figure 2 shows that the GNSS VSM retrievals are more sensitive to light rainfall events than in situ VSM observations at $5 \mathrm{~cm}$ depth. Such events occur during the summer and autumn of 2016. It can be observed that while GNSS VSM estimates peak at the same time as light rain, the diffusion of water in the soil does not reach the probes at $5 \mathrm{~cm}$ depth. This is why the GNSS VSM tends to be larger than in situ VSM. This difference reduces the correlation and increases the errors and can be attributed to a GNSS-IR sensing depth less than $5 \mathrm{~cm}$ (Chew et al., 2014; Shellito et al., 2016), in relation to vegetation litter effects (see Sect. 5.3).

In the following subsections, more detailed comparisons are presented for antenna heights of 29.4 and $3.3 \mathrm{~m}$.

\subsection{VSM estimates from a GNSS antenna at $29.4 \mathrm{~m}$ above the soil}

In most previous studies, VSM was retrieved from GNSS antennas at about 2 or $3 \mathrm{~m}$ above the soil surface. Increasing the antenna height can significantly expand the size of the observed areas. In this study, the impact of using a $29.4 \mathrm{~m}$ antenna on VSM retrievals is assessed using TS1 and TS2 data. The whole observation area for each track is about $900 \mathrm{~m}^{2}$ or even larger. The grass is cut in TS1, before 7 October 2015. Before grass cutting, the maximum simulated aboveground dry biomass is about $0.25 \mathrm{~kg} \mathrm{~m}^{-2}$ (Fig. 2). For TS1, $A_{\text {norm }}$ values are more often than not above 0.78 (Fig. 2). Above this threshold value, the vegetation effects are not significant (Chew et al., 2016). From mid-August to mid-September (before the start of grass cutting), $A_{\text {norm }}$ is slightly smaller than the threshold value, but VSM can be estimated at these dates. Moreover, no grass cutting effects are observed in the $A_{\text {norm }}$ values, which also shows that vegetation effects are not significant. The VSM retrievals, using the L2C SNR data, are compared in Fig. 4 with in situ VSM observations at a depth of $5 \mathrm{~cm}$. Figure 5 shows that VSM retrievals tend to be larger than the in situ observations. Similar results are obtained from the L5 SNR data (Fig. 5). The L2C and L5 VSM retrieval scores are presented in Table 3.
Figure 5 and Table 3 show that VSM retrievals using L5 SNR data are very close to those derived from L2C SNR data. The retrieval accuracies from L2C and L5 SNR data are similar (Table 3), showing that both L2C and L5 SNR data can be used to retrieve VSM. In Table 2, L2C and L5 SNR data are combined. Results for TS1 in Table 2 show slightly improved scores with respect to those in Table 3. This can be explained by the larger number of available satellite tracks per day. It is interesting to note that results very similar to those presented in Fig. 5 can be obtained by multiplying the $S$ value used by Chew et al. (2016) by 0.6 (not shown).

Overall, the scores obtained during TS1, at a height of $29.4 \mathrm{~m}$ and a sampling interval of $10 \mathrm{~s}$ are comparable to those obtained in other time segments, including TS2 with a sampling interval of $1 \mathrm{~s}$. The scores (Table 2) in TS2 are similar to the scores in TS1. This does not mean that there is no effect from the sampling interval because vegetation conditions are different in TS1 and TS2. TS2 corresponds to a vegetation growing period. Vegetation growth impacts the reflecting surface and has an impact on the SNR data as illustrated by the fast decrease of $A_{\text {norm }}$ values in Fig. 2. Moreover, the SNR data in TS4 (after grass cutting) are used to assess the impact of changing the sampling interval, without change in vegetation conditions. This is discussed in Sect. 5.4.

\subsection{Removing vegetation growth effects from VSM retrievals}

Substantial vegetation effects are observed during TS3, at the end of the growing season of 2016. This is evidenced by $A_{\text {norm }}$ values lower than 0.78 (Fig. 2). Grass is cut at the end of TS3 (before 9 July 2016). After grass cutting, the SNR $A_{\text {norm }}$ values gradually rise to a relatively large value (above $0.78)$. For example, the daily mean L2C $A_{\text {norm values are }}$ $0.67,0.69,0.75$ and 0.86 from 6 to 9 July 2016, respectively.

In order to remove vegetation effects, the SNR data before and after cutting are considered as distinct datasets (see Sect. 3.1 and 3.2). SNR data are used, time segment by time segment, to obtain soil wetness index and then VSM estimates. The observed soil moisture minimum and maximum values are derived for each time segment. For L2C (L5), 10 (6) satellite tracks out of 36 (21) are selected for use during TS3. Figure 6a shows the VSM retrievals for each time segment TS3 and TS4 for L2C SNR data after removing vegetation effects by applying the Zhang et al. (2017) method. The corresponding scores are listed in Table 4. Similar results are obtained for L5 and both L2C and L5 SNR data (Table 4). Results obtained by applying the Zhang et al. (2017) method to the merged time segments (TS3 and TS4) for L2C SNR data are also shown in Fig. 6 and in Table 4. In this case, SNR-derived VSM are too dry before the cutting and too wet after the cutting (Fig. 6b). 


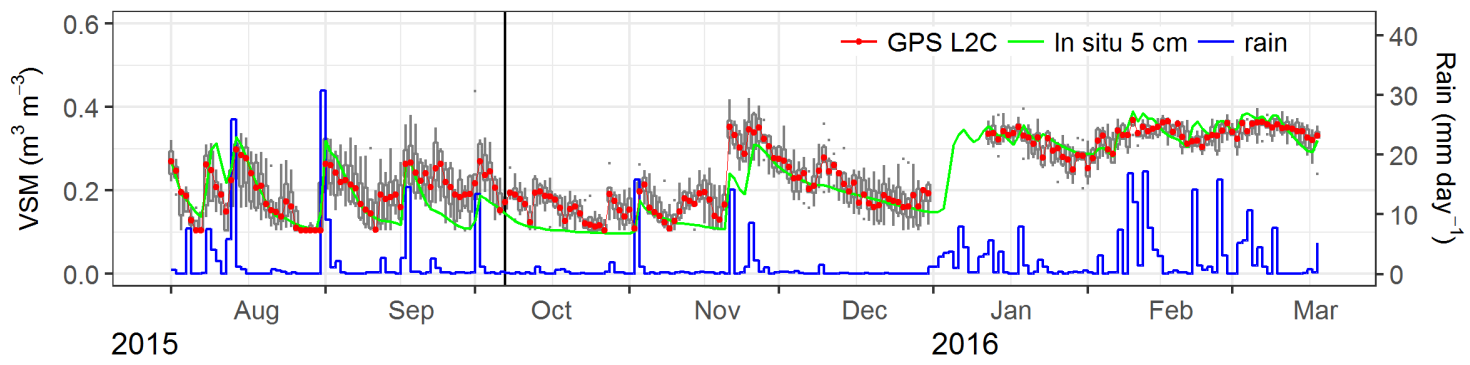

Figure 4. Median of the daily VSM retrievals $(N=220$, red dots) and their daily statistical distribution (grey box plots) for six available satellite tracks. Daily mean in situ VSM observations at a depth of $5 \mathrm{~cm}$ are shown by the green line. The black line indicates the grass cutting before 7 October 2015 . The blue line represents the rainfall (daily precipitation in mm day ${ }^{-1}$ ). The L2C SNR data acquired by the $29.4 \mathrm{~m}$ antenna with a $10 \mathrm{~s}$ sampling interval were used to retrieve VSM during TS1 (vegetation senescence and after cutting). Boxes: 25th75th percentiles; bars: maximum (minimum) values below (above) $1.5 \mathrm{IQR}$ (interquartile range; corresponding to the 25th-75th percentile interval); dots: data outside the 1.5 IQR interval.
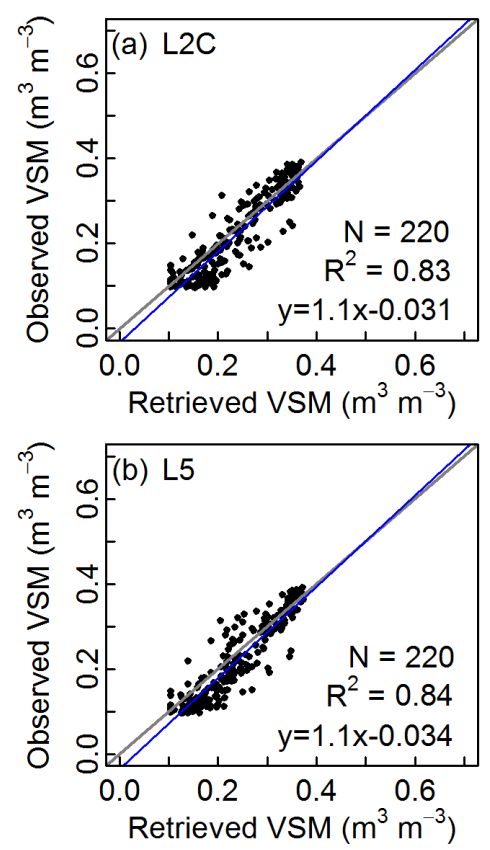

Figure 5. Scatter plots of daily mean in situ VSM observations at a depth of $5 \mathrm{~cm}$ vs. GNSS VSM retrievals $(N=220)$ : from (a) L2C SNR data, and (b) L5 SNR data. The SNR data acquired by the $29.4 \mathrm{~m}$ antenna with a $10 \mathrm{~s}$ sampling interval during TS1 were used.

\section{Discussion}

\subsection{Why should growth and senescence be treated separately?}

While VSM could not be retrieved by Zhang et al. (2017) after wheat tillering, i.e., for plant heights larger than $0.2 \mathrm{~m}$, we could retrieve scaled VSM values throughout time segments of the grass growing and senescence phases. However, retrieving VSM values in $\mathrm{m}^{3} \mathrm{~m}^{-3}$ was challenging and re-
Table 4. Soil moisture scores between daily mean in situ VSM observations at a depth of $5 \mathrm{~cm}$ and GNSS VSM retrievals (either L2C or L5 or both) during TS3 and TS4 (SNR data from the $3.3 \mathrm{~m}$ antenna with $1 \mathrm{~s}$ sampling interval from 8 June to 6 October 2016). The Zhang et al. (2017) method is used for separated time segments, and also for merged time segments. MAE, RMSE, SDD and $N$ are defined in Table 2.

\begin{tabular}{lrrrr}
\hline Time segments & \multicolumn{3}{c}{$\begin{array}{c}\text { Separate TS3 } \\
\text { and TS4 }\end{array}$} & $\begin{array}{r}\text { Merged TS3 } \\
\text { and TS4 }\end{array}$ \\
\cline { 2 - 4 } Signal & L2C & L5 & L2C and L5 & L2C \\
\hline$N$ & 121 & 121 & 121 & 121 \\
Mean bias $\left(\mathrm{m}^{3} \mathrm{~m}^{-3}\right)$ & 0.010 & 0.011 & 0.010 & 0.025 \\
MAE $\left(\mathrm{m}^{3} \mathrm{~m}^{-3}\right)$ & 0.019 & 0.018 & 0.018 & 0.044 \\
RMSE $\left(\mathrm{m}^{3} \mathrm{~m}^{-3}\right)$ & 0.027 & 0.027 & 0.027 & 0.050 \\
SDD $\left(\mathrm{m}^{3} \mathrm{~m}^{-3}\right)$ & 0.026 & 0.025 & 0.025 & 0.044 \\
$R^{2}$ & 0.55 & 0.60 & 0.57 & 0.03 \\
\hline
\end{tabular}

quired a seasonal rescaling to account for vegetation effects (see Fig. 7).

Section 4.3 showed that the VSM retrieval from SNR data during TS3 is of lower quality than during TS4, i.e., after cutting the vegetation. Not all satellite tracks can be used (Table 1) and skill scores are systematically worse (Table 2). Moreover, Fig. 6 shows that a specific calibration (see Sect. 3.2) of the retrieval method is needed for TS3. Because the retrieval method is based on the minimum phase which is related to the vegetation height and density, the lack of a priori information about this factor is likely to trigger marked discrepancies.

Based on Eq. (1), SNR amplitude $A$ and SNR phase $\phi$ are calculated using the LSE method, assuming that the relative antenna height $\left(H_{0}\right)$ for each satellite track is constant across dates and ignoring the impact of the elevation angle change in $A$ (Larson et al., 2008, 2010). The median value of the derived effective antenna height from the SNR data by the Lomb-Scargle periodogram method is considered as 

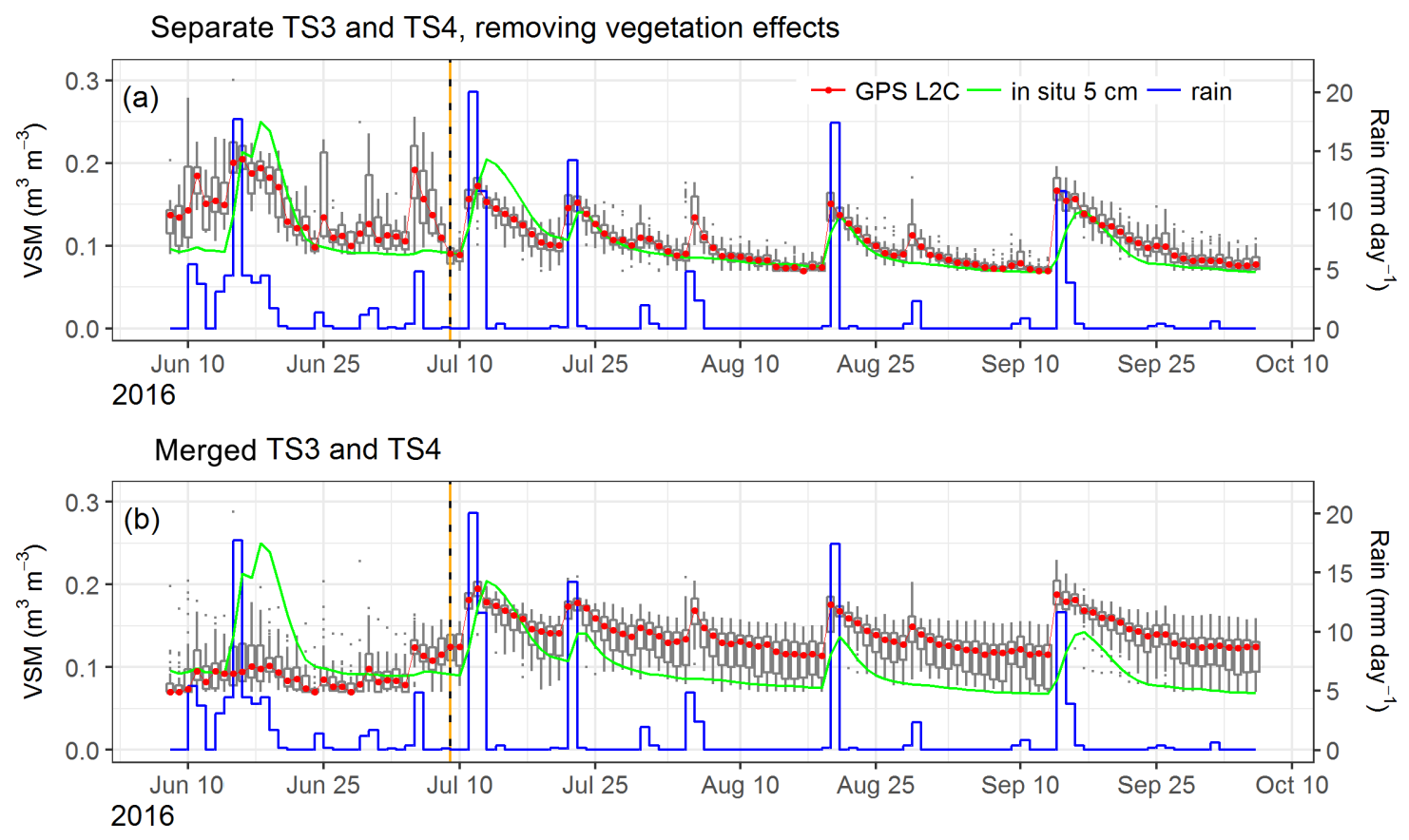

Figure 6. Median of the daily VSM retrievals (red lines) with (a) separate TS3 and TS4 and removing vegetation effects, and (b) merged TS3 and TS4, using L2C SNR data (from the $3.3 \mathrm{~m}$ antenna with $1 \mathrm{~s}$ sampling interval) during TS3 and TS4 (from 8 June to 6 October 2016 ). Daily mean in situ VSM observations at a depth of $5 \mathrm{~cm}$ are shown by the green lines. The blue lines represent the rainfall (daily precipitation in $\mathrm{mm} \mathrm{day}^{-1}$ ). The black/orange dashed line indicates the grass cutting before 9 July 2016.
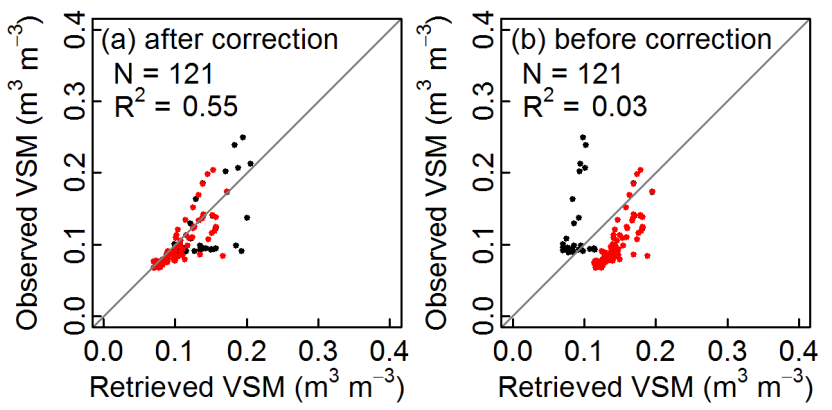

Figure 7. Scatter plots of daily mean in situ VSM observations $(N=121)$ at a depth of $5 \mathrm{~cm}$ vs. GPS L2C retrievals: (a) after vegetation effect correction (with separate TS3 and TS4, corresponding to Fig. 6a) and (b) before correction (with merged TS3 and TS4, corresponding to Fig. 6b). The L2C SNR data acquired by the $3.3 \mathrm{~m}$ antenna with $1 \mathrm{~s}$ sampling interval were used. Black dots represent the retrievals $(N=31)$ during TS3; red dots $(N=90)$ represent the retrievals during TS4 (after grass cutting).

the value of the a priori $H_{0}$ for each satellite track (Chew et al., 2016). This hypothesis is only valid for the dates when the surface is not covered with snow or dense vegetation. Although the real effective antenna height may vary from one day to another, a constant value of $H_{0}$ is used through time for a given satellite track. This assumption is made in order to ensure the consistency of $\phi$ time series across dates. The a priori $H_{0}$ value affects the sinusoid fit, and might cause a systematic bias of $A$ and $\phi$ across dates. When there are significant vegetation effects, the vegetation height affects the effective antenna height (Zhang et al., 2017). This explains why the obtained VSM retrieval time series with merged time segments are not continuous (Fig. 6). Segment by segment normalization is useful for removing such systematic biases and to remove vegetation effects from VSM retrieval. It can be considered as a vegetation correction method.

Figure 7 illustrates the improvement associated with the vegetation correction. The systematic bias caused by the mismatch in $H_{0}$ is shown. Without vegetation correction, the VSM retrievals do not correlate with the observed VSM $\left(R^{2}=0.03\right)$. On the other hand, the vegetation correction removes the differences between TS 3 and TS4 caused by using the same $H_{0}$ in both time segments, and the VSM retrievals are more consistent $\left(R^{2}=0.55\right)$. Figure 7 clearly shows that using GNSS-IR to retrieve VSM values in $\mathrm{m}^{3} \mathrm{~m}^{-3}$ when significant changes in vegetation effects occur is challenging. The need to harmonize VSM retrievals from TS3 and TS4 is related to the cutting of the grass when vegetation effects are pronounced ( $A_{\text {norm }}$ is lower than 0.78 , see Fig. 1$)$.

As a consequence, monitoring VSM using a GNSS network could be difficult when vegetation effects are noticeable. However, we show that one may use the information from $A_{\text {norm }}$ data to define time segments for which scaled 
VSM time series are valid. For example, grass cutting can be detected from the rapid rise in $A_{\text {norm }}$ value.

In this study, we used independent VSM in situ observations to harmonize the VSM time series across TS3 and TS4. Since in situ observations are not extensively available, this technique is not readily applicable at other sites. In practice, one could possibly use a data assimilation framework able to integrate the VSM retrievals into model VSM simulations such as those produced by the ISBA land surface model (Albergel et al., 2017). In such land data assimilation systems (LDASs), a complex seasonal rescaling of VSM observations is needed (Reichle and Koster, 2004; Draper and Reichle, 2015), especially when the observations are not properly decontaminated from vegetation effects (Stoffelen et al., 2017). Our results show that using this rescaling technique would be feasible since the ISBA simulations of VSM correlate well with the retrieved VSM (Fig. 8). The main reason for this result is that ISBA is forced by the SAFRAN atmospheric analysis, incorporating a large number of in situ rain gauge observations (Sect. 2.1). This is another way of using ancillary in situ observations.

\subsection{Are grassland and cropland vegetation effects comparable?}

The effects of vegetation on GNSS SNR data are threefold: from plant height, aboveground biomass and litter. At the end of the growing season, plant height and aboveground biomass values can be much larger for annual crops than for grass. On the other hand, while litter is usually missing during the growing phase of annual crops, litter is characteristic of grasslands (Quested and Eriksson, 2016).

Over our grassland site, the measured grass height at the end of the growing period is $30 \mathrm{~cm}$ on 22 June 2016 . The grass height is then only slightly larger than one GNSS wavelength ( $\sim 25 \mathrm{~cm}$ for L5). The simulated aboveground biomass by ISBA is shown in Fig. 2. During the summer of 2015, the maximum aboveground biomass slightly exceeds $0.25 \mathrm{~kg} \mathrm{~m}^{-2}$. This short period coincides with $A_{\text {norm }}$ values slightly lower than the 0.78 threshold. In June 2016, before the cutting, the aboveground biomass ranges between 0.25 and $0.50 \mathrm{~kg} \mathrm{~m}^{-2}$. The corresponding $A_{\text {norm }}$ drops below 0.78 , showing that vegetation effects are significant. The simulated green aboveground biomass is $0.39 \mathrm{~kg} \mathrm{~m}^{-2}$ on 22 June 2016, very close to the observed value of $0.37 \mathrm{~kg} \mathrm{~m}^{-2}$. The litter dry mass is not simulated but a value of $0.29 \mathrm{~kg} \mathrm{~m}^{-2}$ is obtained from in situ observation at the same date, consisting of $0.23 \mathrm{~kg} \mathrm{~m}^{-2}$ of dead leaf material and of $0.06 \mathrm{~kg} \mathrm{~m}^{-2}$ of decomposed leaves. This represents $44 \%$ of the total aboveground organic material.

Zhang et al. (2017) showed that over a wheat field the vegetation gradually replaces the soil as the dominant reflecting surface when plant height becomes comparable to, or larger than, one wavelength, even at relatively low values of the aboveground biomass (an estimate of $0.08 \mathrm{~kg} \mathrm{~m}^{-2}$ is given). In such conditions the $A_{\text {norm }}$ drops below 0.78 and the SNR phase is no longer related to soil moisture (Zhang et al., 2017).

This study shows that VSM retrieval above these biomass and plant height thresholds are feasible for grass. However, a limited number of suitable tracks, less affected by vegetation, have to be selected using the grass cutting event (see Sect. 3.2). In real practical applications, such tracks are not a priori known and retrieving VSM would be challenging when vegetation effects are significant.

\subsection{Does the litter affect the GNSS VSM retrieval?}

In order to analyze the possible impact of litter on the differences between GNSS VSM and either in situ VSM or ISBA VSM, in situ VSM observations at $5 \mathrm{~cm}$, in situ VSM observations at $1 \mathrm{~cm}$ and ISBA VSM simulations at $1 \mathrm{~cm}$ are compared with the GNSS VSM retrievals. The GNSS VSM is retrieved applying the Zhang et al. (2017) method to both L2C and L5 SNR data, and the vegetation effects are removed from the retrievals. For ensuring the comparability of these various soil moisture estimates, GNSS retrievals, ISBA $1 \mathrm{~cm}$ simulations, in situ $1 \mathrm{~cm}$ observations and in situ $5 \mathrm{~cm}$ observations are scaled to dimensionless values.

Figure 8 shows a comparison between the four scaled VSM time series during TS3 and TS4. Soil moisture values tend to increase drastically during precipitation events. Most of the VSM peaks observed in $1 \mathrm{~cm}$ in situ observations are also found in $5 \mathrm{~cm}$ observations, except for 5-7 July and 5 August 2016. On the other hand, GNSS VSM peaks can occur while in situ VSM observations do not display any response to rain, e.g., on $8-14,25$ and 30 June, 3031 July, and 29 August 2016. A contrasting result is found comparing GNSS and ISBA VSM estimates, which peak, more often than not, at the same time. As a consequence, the GNSS VSM estimates correlate much better with ISBA $\operatorname{VSM}\left(R^{2}=0.82\right)$ than with in situ VSM observations at $1 \mathrm{~cm}$ $\left(R^{2}=0.63\right)$ and at $5 \mathrm{~cm}\left(R^{2}=0.57\right)$.

The scores resulting from the comparison between scaled VSM validation data and GNSS VSM estimates are separately recorded in Table 2 for each time segment. The highest correlations are with ISBA simulations at $1 \mathrm{~cm}$, for all time segments. The scores based on in situ VSM observations at $1 \mathrm{~cm}$ are similar to those based on in situ VSM observations at $5 \mathrm{~cm}$. For TS4, the correlation with in situ VSM observations at $1 \mathrm{~cm}$ is much higher than with those at $5 \mathrm{~cm}$. The main difference between observations at $1 \mathrm{~cm}$ and at $5 \mathrm{~cm}$ is that the former respond to rainfall events more rapidly. This is illustrated by Fig. 8 for events occurring after 9 July 2016 (TS4). The differences observed between GNSS VSM estimates and in situ VSM observations at $1 \mathrm{~cm}$ can be explained by the interception of light rain by the litter. Water contained in the litter tends to directly reflect the GNSS signal and to prevent the GNSS signal from further penetrating into the soil. This difference is not observed with ISBA simulations 

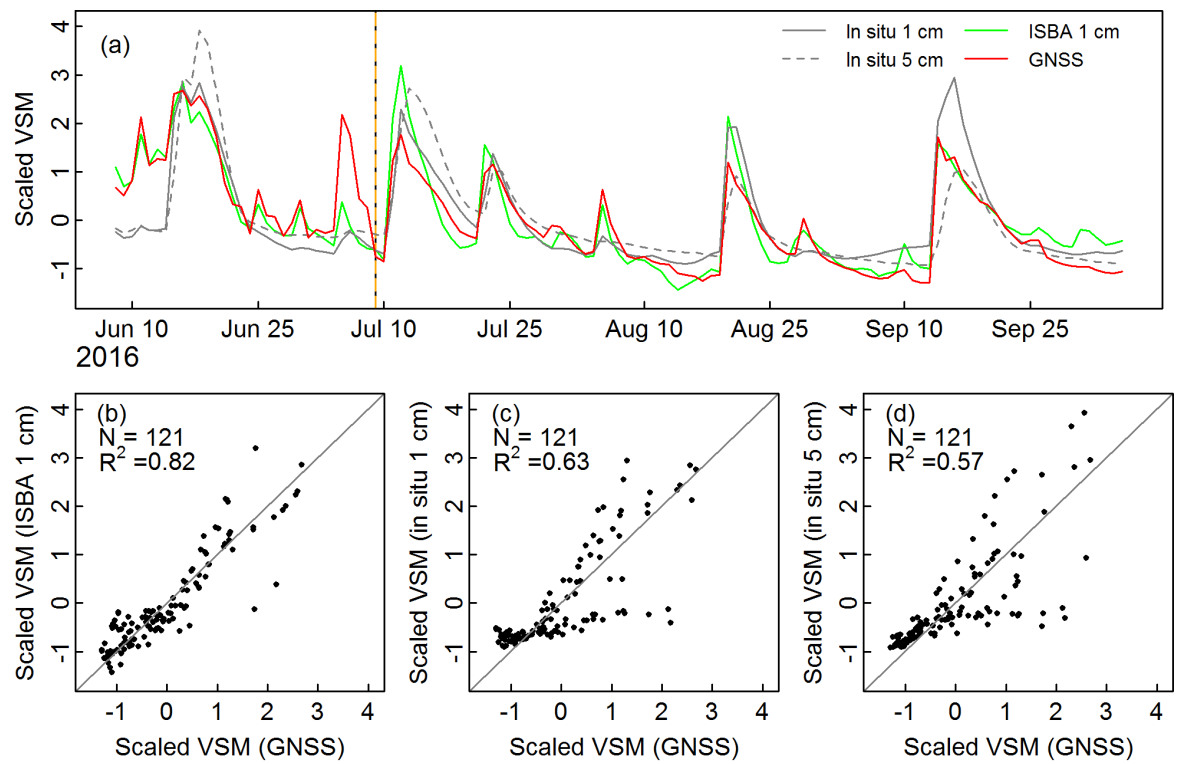

Figure 8. (a) Scaled GNSS VSM retrieval time series (red line, $N=121$ ) using both L2C and L5 SNR data during separate TS3 and TS4, scaled ISBA $1 \mathrm{~cm}$ simulations (green line) and scaled in situ VSM observations at $1 \mathrm{~cm}$ (grey solid line) and at $5 \mathrm{~cm}$ (grey dashed line). The SNR data acquired by the $3.3 \mathrm{~m}$ antenna with $1 \mathrm{~s}$ sampling interval were used during TS3 and TS4. The black/orange dashed line indicates the grass cutting of 9 July 2016. (b, c, d) Scatter plots of scaled ISBA VSM simulations at $1 \mathrm{~cm}$, scaled in situ VSM observations at $1 \mathrm{~cm}$ and scaled in situ VSM observations at $5 \mathrm{~cm}$ vs. scaled GNSS VSM retrievals, respectively.
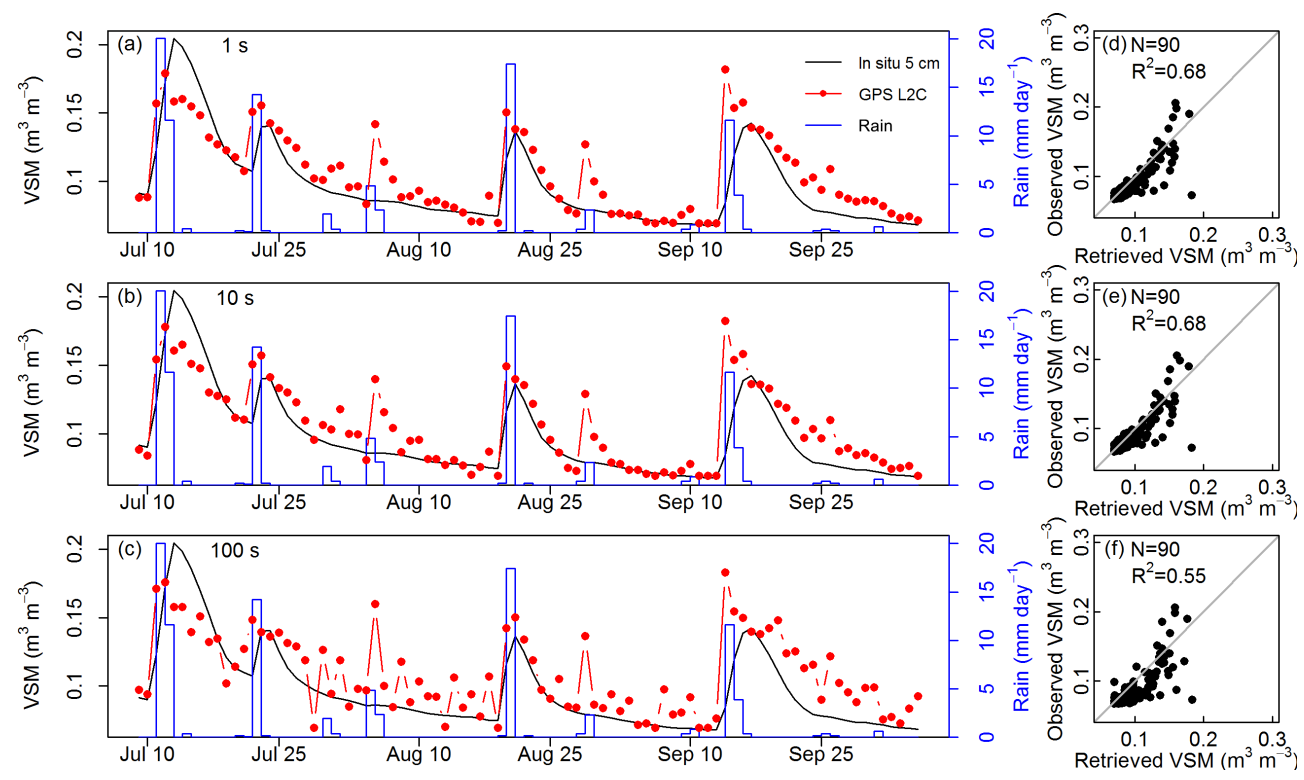

Figure 9. L2C SNR VSM retrieval time series using GPS PRN 10 ascending tracks with different sampling intervals: (a) $1 \mathrm{~s}$, (b) $10 \mathrm{~s}$ and (c) $100 \mathrm{~s}$. The L2C SNR data acquired by the $3.3 \mathrm{~m}$ antenna during TS4 (after grass cutting in July 2016) were used. Their corresponding scatter plots are shown in (d), (e) and (f), respectively. Daily mean in situ VSM observations at a depth of $5 \mathrm{~cm}$ (black lines) are shown in the left subfigures, and the blue lines represent the daily precipitation in $\mathrm{mm} \mathrm{day}^{-1}$.

because the litter is not implemented in this version of the ISBA model. The good correspondence between ISBA and GNSS VSM estimates can be considered as an artifact: ISBA simulates a VSM peak which does not exist, and the GNSS SNR data are sensitive to a sudden increase in the litter wa- ter content and/or to the rain intercepted by the litter or by the leaves. Another demonstration of the impact of the litter effects can be made, removing rainy days from TS4. The $R^{2}$ score in Table 2 then rises from 0.65 to 0.83 . 


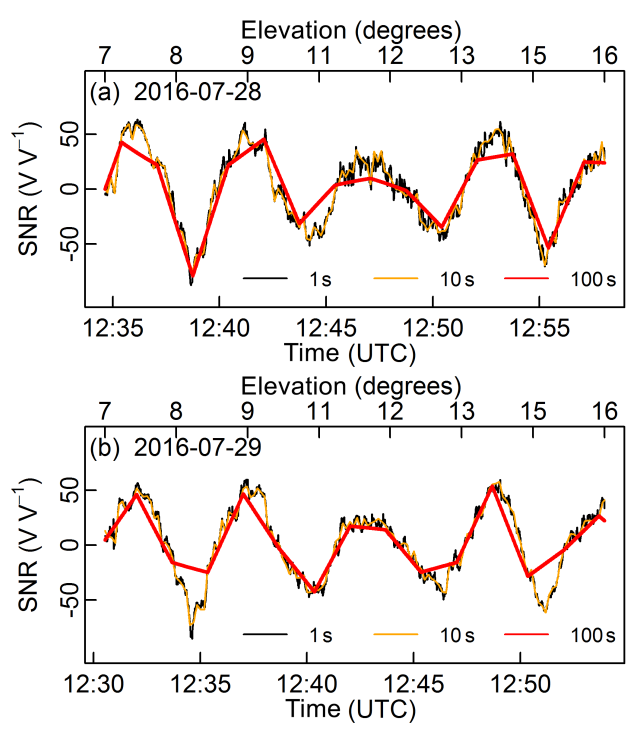

Figure 10. Two examples of L2C SNR data sets (from the GPS PRN 10 ascending tracks) acquired by the $3.3 \mathrm{~m}$ antenna at two contiguous dates: (a) 28 July and (b) 29 July 2016. SNR data with three different sampling intervals at 1,10 and $100 \mathrm{~s}$ are shown in black, orange and red lines, respectively.

\subsection{Does the sampling interval affect the VSM retrieval?}

When the antenna height increases, the size of the observing areas is extended. But at the same time the period of the SNR data decreases (Eq. 1), and a smaller sampling interval is needed to ensure the usability of the SNR data for VSM retrieval. On the other hand, because the SNR period from a high antenna is much smaller, it is possible to use smaller elevation angle ranges and shorter observing time periods per track. The number of complete SNR waveforms is much larger than using a low antenna. We investigate the impact of under-sampling for the $3.3 \mathrm{~m}$ antenna and for the $29.4 \mathrm{~m}$ antenna. It should be noted that in the examples illustrated by Figs. 9, 10, and 11 the SNR frequency is always lower than the Nyquist frequency.

First, an example of the impact of the sampling interval for the $3.3 \mathrm{~m}$ antenna is shown in Fig. 9. L2C SNR observations $(N=90)$ from GPS PRN 10 ascending tracks during TS4 (after grass cutting) are used to retrieve VSM using various sampling intervals. The Zhang et al. (2017) method is used based on the original $1 \mathrm{~s}$ sampling interval and on degraded sampling intervals of 10 and 100 s. During TS4, $A_{\text {norm }}$ is above 0.78 (Fig. 2), which also shows that vegetation effects are not significant (Chew et al., 2016). This is a rather dry period, but a few rainfall events are observed. They cause changes in the in situ VSM observations at $5 \mathrm{~cm}$, which range between 0.07 and $0.21 \mathrm{~m}^{3} \mathrm{~m}^{-3}$. In Fig. 9, the highest correlation $\left(R^{2}=0.68\right)$ is for the smallest sampling intervals $(1$ and $10 \mathrm{~s})$, and the lowest correlation $\left(R^{2}=0.55\right)$
Table 5. Soil moisture scores from the comparison between daily mean in situ VSM observations at a depth of $5 \mathrm{~cm}$ and GNSS VSM retrievals during TS4 (after grass cutting, from 9 July to 6 October 2016). The L2C SNR data from GPS PRN 10 ascending tracks were used, which were acquired by the $3.3 \mathrm{~m}$ antenna. MAE is the mean absolute error, RMSE is the root mean square error and SDD is the standard deviation of difference.

\begin{tabular}{lrrr}
\hline Sampling interval & $1 \mathrm{~s}$ & $10 \mathrm{~s}$ & $100 \mathrm{~s}$ \\
\hline$N$ & 90 & 90 & 90 \\
Mean bias $\left(\mathrm{m}^{3} \mathrm{~m}^{-3}\right)$ & 0.009 & 0.008 & 0.012 \\
MAE $\left(\mathrm{m}^{3} \mathrm{~m}^{-3}\right)$ & 0.013 & 0.013 & 0.018 \\
SDD $\left(\mathrm{m}^{3} \mathrm{~m}^{-3}\right)$ & 0.018 & 0.018 & 0.021 \\
RMSE $\left(\mathrm{m}^{3} \mathrm{~m}^{-3}\right)$ & 0.020 & 0.020 & 0.025 \\
$R^{2}$ & 0.68 & 0.68 & 0.55 \\
\hline
\end{tabular}

is observed for the largest sampling interval (100s). The corresponding statistical scores, resulting from the comparison between in situ VSM observations at a depth of $5 \mathrm{~cm}$ and GNSS VSM retrievals are shown in Table 5. As for $R^{2}$, RMSE and SDD for 1 and $10 \mathrm{~s}$ sampling intervals are similar $\left(\mathrm{RMSE}=0.020 \mathrm{~m}^{3} \mathrm{~m}^{-3}\right.$ and $\mathrm{SDD}=0.018 \mathrm{~m}^{3} \mathrm{~m}^{-3}$ ), and denote lower skill for the $100 \mathrm{~s}$ sampling interval $\left(\mathrm{RMSE}=0.025 \mathrm{~m}^{3} \mathrm{~m}^{-3}\right.$ and $\mathrm{SDD}=0.021 \mathrm{~m}^{3} \mathrm{~m}^{-3}$ ). Much more day-to-day variability is observed in the retrievals using a 100 s sampling interval. The impact on the SNR information content of degrading the sampling interval may vary from one day to another. This is illustrated by Fig. 10 for two contiguous days (28 and 29 July 2016). The under-sampling effect at $100 \mathrm{~s}$ is more pronounced on 29 July than on 28 July. More pit and peak information is missing on 29 July. This tends to trigger a sharp decrease in the retrieved VSM values. On the other hand, under-sampling tends to increase the retrieved VSM on 28 July. As a result, the retrieved VSM drops by $-0.050 \mathrm{~m}^{3} \mathrm{~m}^{-3}$ from 28 to 29 July while the in situ VSM at $5 \mathrm{~cm}$ only changes by $-0.004 \mathrm{~m}^{3} \mathrm{~m}^{-3}$.

SNR amplitudes are also affected by the sampling interval in TS4. For 29 July 2016, the estimated SNR amplitude is $26 \mathrm{~V} \mathrm{~V}^{-1}$ for both 1 and $10 \mathrm{~s}$ sampling intervals, but only $18 \mathrm{~V} \mathrm{~V}^{-1}$ for the $100 \mathrm{~s}$ sampling interval. For this example track data acquired by the $3.3 \mathrm{~m}$ antenna, the SNR period is about $330 \mathrm{~s}$. There are about 330,33 and 3 samples in a complete waveform for 1,10 and $100 \mathrm{~s}$ sampling intervals, respectively. Obviously, the $100 \mathrm{~s}$ sampling interval does not provide enough samples to retrieve VSM. On the other hand, using a $10 \mathrm{~s}$ sampling interval is sufficient for the SNR data acquired by the $3.3 \mathrm{~m}$ antenna after cutting the grass.

For the $29.4 \mathrm{~m}$ antenna, the sensitivity to the sampling interval is more critical. Figure 11 shows the SNR oscillations for the GPS PRN 25 ascending track. The SNR period is only about $38 \mathrm{~s}$. With $10 \mathrm{~s}$ sampling interval, three or four samples are available for a complete waveform. This is about the same situation as for the $100 \mathrm{~s}$ sampling interval for the $3.3 \mathrm{~m}$ antenna. Figure 11a shows that pit and peak information is 

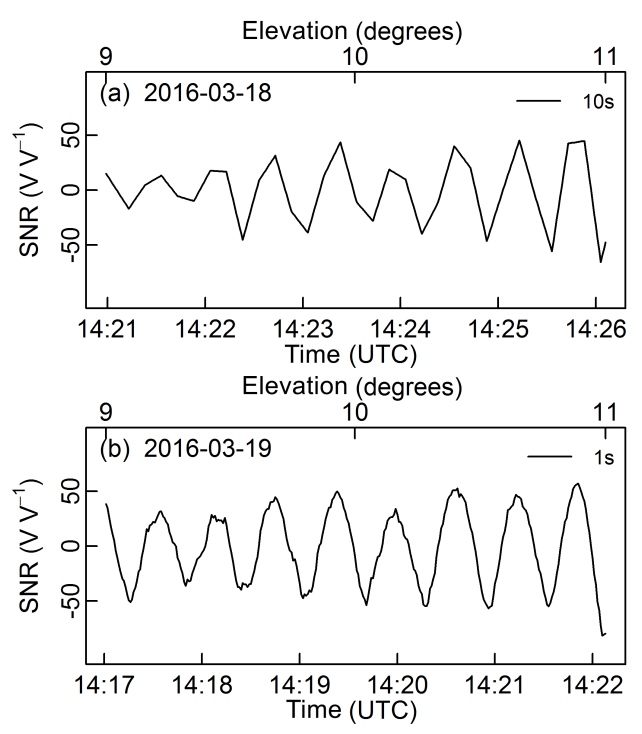

Figure 11. Two examples of L2C SNR data sets (from the GPS PRN 25 ascending tracks) acquired by the $29.4 \mathrm{~m}$ antenna at two contiguous dates: (a) 18 March 2016 (with 10 s sampling interval) and (b) 19 March 2016 (with 1 s sampling interval).

missing on 18 March 2016 with respect to the $1 \mathrm{~s}$ sampling interval data on the next day in Fig. 11b. Nevertheless, Table 2 shows that the $10 \mathrm{~s}$ under-sampling had a limited impact on VSM retrievals during TS1 since the best scores are observed during this segment. This paradoxical result can be explained by the prior use of the in situ VSM data to select the satellite tracks and the satellite elevation angles (see Sect. 2.2).

\section{Conclusions}

GPS L2C and L5 SNR data were obtained at a grassland site in southwestern France during a period of 15 months. A dimensionless scaled wetness index was derived from the SNR observations based on the GNSS-IR technique, using indiscriminately L2C or L5 signals. Surface soil moisture was derived from this scaled wetness index. We show that accurately estimating soil moisture in units of $\mathrm{m}^{3} \mathrm{~m}^{-3}$ over such a densely vegetated site is challenging. In order to efficiently limit the impact of perturbing vegetation effects, the grass growth period and the senescence period should be treated separately. While the vegetation biomass effect can be corrected for, the litter water interception influences the observations and cannot be easily accounted for. Overall, a precision of $0.035 \mathrm{~m}^{3} \mathrm{~m}^{-3}$ is achieved for the whole meadow growing cycle, and of $0.018 \mathrm{~m}^{3} \mathrm{~m}^{-3}$ after grass cutting. A suitable sampling interval should be used, dependent on the antenna height and elevation angle range. Positioning the antenna high up (at $29.4 \mathrm{~m}$ in this study) in order to observe a larger area enhances the impact of under-sampling. The signal sam- pling interval should be better than $10 \mathrm{~s}$ in this case. More experiments over contrasting vegetation types are needed to further examine the feasibility of integrating GNSS-IR retrievals in land surface models. Land data assimilation systems are usually used for satellite observations but can also integrate ground observations. In such a framework, model simulations of vegetation biomass and soil moisture could be combined with GNSS-IR retrievals. Proposing a complete protocol to apply this method to local GNSS antennas would require observations at a large number of sites. More research is needed to use GNSS-IR in densely vegetated areas.

Data availability. The data used in this work are available for research from the corresponding author.

Competing interests. The authors declare that they have no conflict of interest.

Acknowledgements. The work of Sibo Zhang was supported by the STAE (Sciences et Technologies pour l'Aéronautique et l'Espace) foundation, in the framework of the PRISM (Potentialités de la Réflectométrie GNSS In-Situ et Mobile) project. The authors would also like to thank Eric Moulin and Joel Barrié (CNRM) for their technical support during the field campaign and Anne Belleudy and Diane Tzanos (CNRM) for performing biomass observations.

Edited by: Miriam Coenders-Gerrits

Reviewed by: two anonymous referees

\section{References}

Albergel, C., Munier, S., Leroux, D. J., Dewaele, H., Fairbairn, D., Barbu, A. L., Gelati, E., Dorigo, W., Faroux, S., Meurey, C., Le Moigne, P., Decharme, B., Mahfouf, J.-F., and Calvet, J.-C.: Sequential assimilation of satellite-derived vegetation and soil moisture products using SURFEX_v8.0: LDAS-Monde assessment over the Euro-Mediterranean area, Geosci. Model Dev., 10, 3889-3912, https://doi.org/10.5194/gmd-10-3889-2017, 2017.

Bilich, A., Larson, K. M., and Axelrad, P.: Modeling GPS phase multipath with SNR: Case study from the Salar de Uyuni, Boliva, J. Geophys. Res., 113, 2156-2202, https://doi.org/10.1029/2007JB005194, 2008.

Chan, S. K., Bindlish, R., O’Neill, P. E., Njoku, E., Jackson, T., Colliander, A., Chen, F., Burgin, M., Dunbar, S., Piepmeier, J., Yueh, S., Entekhabi, D., Cosh, M. H., Caldwell, T., Walker, J., Wu, X., Berg, A., Rowlandson, T., Pacheco, A., McNairn, H., Thibeault, M., Martínez-Fernández, J., GonzálezZamora, A., Seyfried, M., Bosch, D., Starks, P., Goodrich, D., Prueger, J., Palecki, M., Small, E. E., Zreda, M., Calvet, J.-C., Crow, W., and Kerr, Y.: Assessment of the SMAP passive soil moisture product, IEEE T. Geosci. Remote S., 54, 4994-5007, https://doi.org/10.1109/TGRS.2016.2561938, 2016.

Chew, C. C., Small, E. E., Larson, K. M., and Zavorotny, V. U.: Effects of near-surface soil moisture on GPS 
SNR data: development of a retrieval algorithm for soil moisture, IEEE T. Geosci. Remote S., 52, 537-543, https://doi.org/10.1109/TGRS.2013.2242332, 2014.

Chew, C. C., Small, E. E., and Larson, K. M.: An algorithm for soil moisture estimation using GPS-interferometric reflectometry for bare and vegetated soil, GPS Solutions, 20, 525-537, https://doi.org/10.1007/s10291-015-0462-4, 2016.

Decharme, B., Boone, A., Delire, C., and Noilhan, J.: Local evaluation of the Interaction between Soil Biosphere Atmosphere soil multilayer diffusion scheme using four pedotransfer functions, J. Geophys. Res., 116, D20126, https://doi.org/10.1029/2011JD016002, 2011.

Dorigo, W. A., Xaver, A., Vreugdenhil, M., Gruber, A., Hegyiová, A., Sanchis-Dufau, A. D., Zamojski, D., Cordes, C, Wagner, W, and Drusch, M.: Global automated quality control of in situ soil moisture data from the International Soil Moisture Network, Vadose Zone J., 12, 21 pp, https://doi.org/10.2136/vzj2012.0097, 2013.

Draper, C. and Reichle, R.: The impact of near-surface soil moisture assimilation at subseasonal, seasonal, and interannual timescales, Hydrol. Earth Syst. Sci., 19, 4831-4844, https://doi.org/10.5194/hess-19-4831-2015, 2015.

Durand, Y., Brun, E., Merindol, L., Guyomarc'h, G., Lesaffre, B., and Martin, E.: A meteorological estimation of relevant parameters for snow models, Ann. Geophys., 18, 65-71, https://doi.org/10.1017/S0260305500011277, 1993.

Durand, Y., Giraud, G., Brun, E., Merindol, L., and Martin, E.: A computer-based system simulating snow-pack structures as a tool for regional avalanche forecasting, Ann. Glaciol., 45, 469-484, https://doi.org/10.1017/S0022143000001337, 1999.

Kerr, Y., Waldteufel, P., Wigneron, J., Martinuzzi, J., Font, J., and Berger, M.: Soil moisture retrieval from space: The Soil Moisture and Ocean Salinity (SMOS) mission, IEEE T. Geosci. Remote, 39, 1729-1735, https://doi.org/10.1109/36.942551, 2001.

Lafont, S., Zhao, Y., Calvet, J.-C., Peylin, P., Ciais, P., Maignan, F., and Weiss, M.: Modelling LAI, surface water and carbon fluxes at high-resolution over France: comparison of ISBA-A-gs and ORCHIDEE, Biogeosciences, 9, 439-456, https://doi.org/10.5194/bg-9-439-2012, 2012.

Larson, K. M.: GPS interferometric reflectometry: applications to surface soil moisture, snow depth, and vegetation water content in the western United States, Wiley Interdisciplinary Reviews: Water, 3, 775-787, https://doi.org/10.1002/wat2.1167, 2016.

Larson, K. M. and Nievinski, F. G.: GPS snow sensing: results from the EarthScope Plate Boundary Observatory, GPS solutions, 17, 41-52, https://doi.org/10.1007/s10291-012-0259-7, 2013.

Larson, K. M., Small, E. E., Gutmann, E. D., Bilich, A. L., Braun, J. J., and Zavorotny, V. U.: Use of GPS receivers as a soil moisture network for water cycle studies, Geophys. Res. Lett., 35, L24405, https://doi.org/10.1029/2008GL036013, 2008.

Larson, K. M., Gutmann, E. D., Zavorotny, V. U., Braun, J. J.,, Williams, M. W., and Nievinski, F. G.: Can we measure snow depth with GPS receivers?, Geophys. Res. Lett., 36, L17502, https://doi.org/10.1029/2009GL039430, 2009.

Larson, K. M., Braun, J. J., Small, E. E., Zavorotny, V. U., Gutmann, E. D., and Bilich, A. L.: GPS multipath and its relation to nearsurface soil moisture content, IEEE J. Sel. Top. Appl., 3, 91-99, https://doi.org/10.1109/JSTARS.2009.2033612, 2010.
Larson, K. M., Small, E. E., Chew, C. C., Nievinski, F. G., Pratt, J., McCreight, J. L., Braun, J., Boniface, K., and Evans, S. G.: PBO H2O: Plate Boundary Observatory Studies of the Water Cycle, American Geophysical Union, Fall Meeting, San Francisco, 913 December 2013.

Masson, V., Le Moigne, P., Martin, E., Faroux, S., Alias, A., Alkama, R., Belamari, S., Barbu, A., Boone, A., Bouyssel, F., Brousseau, P., Brun, E., Calvet, J.-C., Carrer, D., Decharme, B., Delire, C., Donier, S., Essaouini, K., Gibelin, A.-L., Giordani, H., Habets, F., Jidane, M., Kerdraon, G., Kourzeneva, E., Lafaysse, M., Lafont, S., Lebeaupin Brossier, C., Lemonsu, A., Mahfouf, J.-F., Marguinaud, P., Mokhtari, M., Morin, S., Pigeon, G., Salgado, R., Seity, Y., Taillefer, F., Tanguy, G., Tulet, P., Vincendon, B., Vionnet, V., and Voldoire, A.: The SURFEXv7.2 land and ocean surface platform for coupled or offline simulation of earth surface variables and fluxes, Geosci. Model Dev., 6, 929-960, https://doi.org/10.5194/gmd-6-929-2013, 2013.

Morisette, J. T., Baret, F., Privette, J. L., Myneni, R. B., Nickeson, J. E., Garrigues, S., Shabanov, N., Weiss, M., Fernandes, R., Leblanc, S., Kalacska, M., Sánchez-Azofeifa, G. A., Chubey, M., Rivard, B., Stenberg, P., Rautiainen, M., Voipio, P., Manninen, T., Pilant, A. N., Lewis, T. E., Iiames, J. S., Colombo, R., Meroni, M., Busetto, L., Cohen, W., Turner, D. P., Warner, E. D., Petersen, G. W., Seufert, G., and Cook, R.: Validation of global moderate-resolution LAI products: A framework proposed within the CEOS land product validation subgroup, IEEE T. Geosci. Remote, 44, 1804-1817, https://doi.org/10.1109/TGRS.2006.872529, 2006.

Quested, H. and Eriksson, O.: Litter species composition influences the performance of seedlings of grassland herbs, Funct. Ecol., 20, 522-532, https://doi.org/10.1111/j.1365-2435.2006.01131.x, 2016.

Quintana-Segui, P., Lemoigne, P., Durand, Y., Martin, E., Habets, F., Baillon, M., Canellas, C., Franchisteguy, L., and Morel, S.: Analysis of near surface atmospheric variables: Validation of the SAFRAN analysis over France, J. Appl. Meteorol. Clim., 47, 92 107, https://doi.org/10.1175/2007JAMC1636.1, 2008.

Reichle, R. and Koster, R.: Bias reduction in short records of satellite soil moisture, Geophys. Res. Lett., 31, L19501, https://doi.org/10.1029/2004GL020938, 2004.

Rodriguez-Alvarez, N., Vall-llossera, M., Camps, A., Bosch-Lluis, X., Monerris, A., Ramos-Perez, I., Valencia, E., MarchanHernandez, J.F., Martinez-Fernandez, J., Baroncini-Turricchia, G., Perez-Gutierrez, C., and Sanchez, N.: Land geophysical parameters retrieval using the interference pattern GNSS$\mathrm{R}$ technique, IEEE Trans. Geosci. Remote Sens., 49, 71-84, https://doi.org/10.1109/TGRS.2010.2049023, 2011.

Rodríguez-Iturbe, I. and Porporato, A.: Ecohydrology of watercontrolled ecosystems: soil moisture and plant dynamics, University Press, Cambridge, 464 pp., 2007.

Roussel, N., Frappart, F., Ramillien, G., Darrozes, J., Desjardins, C., Gegout, P., Pérosanz, F., and Biancale, R.: Simulations of direct and reflected wave trajectories for groundbased GNSS-R experiments, Geosci. Model Dev., 7, 2261-2279, https://doi.org/10.5194/gmd-7-2261-2014, 2014.

Roussel, N., Ramillien, G., Frappart, F., Darrozes, J., Gay, A., Striebig, N., Biancale, R., Hanquiez, V., and Allain, D.: Sea level monitoring and sea state estimate using a sin- 
gle geodetic receiver, Remote Sens. Environ., 171, 261-277, https://doi.org/10.1016/j.rse.2015.10.011, 2015.

Roussel, N., Frappart, F., Ramillien, G., Darrozes, J., Baup, F., Lestarquit, L., and Ha, M. C.: Detection of Soil Moisture Variations Using GPS and GLONASS SNR Data for Elevation Angles Ranging From $2^{\circ}$ to $70^{\circ}$, IEEE J. Sel. Top. Appl., 9, 4781-4794, https://doi.org/10.1109/JSTARS.2016.2537847, 2016.

Saleh, K., Wigneron, J.-P., Waldteufel, P., de Rosnay, P., Schwank, M., Calvet, J.-C., and Kerr, Y.: Estimates of surface soil moisture under grass covers using L-band radiometry, Remote Sens. Env., 109, 42-53, https://doi.org/10.1016/j.rse.2006.12.002, 2007.

Shellito, P. J., Small, E. E., Colliander, A., Bindlish, R., Cosh, M. H., Berg, A. A., Bosch, D. D., Caldwell, T. G., Goodrich, D. C., McNairn, H., Prueger, J. H., Starks, P. J., van der Velde, R., and Walker, J. P.: SMAP soil moisture drying more rapid than observed in situ following rainfall events, Geophys. Res. Lett., 43, 8068-8075, https://doi.org/10.1002/2016GL069946, 2016.

Small, E. E., Larson, K. M., and Braun, J. J.: Sensing vegetation growth with reflected GPS signals, Geophys. Res. Lett., 37, L12401, https://doi.org/10.1029/2010GL042951, 2010.

Small, E. E., Larson, K. M., Chew, C. C., Dong, J., and Ochsner, T. E.: Validation of GPS-IR soil moisture retrievals: Comparison of different algorithms to remove vegetation effects, IEEE J. Sel. Top. Appl., 9, 4759-4770, https://doi.org/10.1109/JSTARS.2015.2504527, 2016.

Stoffelen, A., Aaboe, S., Calvet, J.-C., Cotton, J., De Chiara, G., Figua-Saldana, J., Mouche, A. A., Portabella, M., Scipal, K., and Wagner, W.: Scientific developments and the EPS-SG scatterometer, IEEE J. Sel. Topics Appl. Earth Obs. Remote Sens., 10, 2086-2097, https://doi.org/10.1109/JSTARS.2017.2696424, 2017.
Vey, S., Güntner, A., Wickert, J., Blume, T., and Ramatschi, M.: Long-term soil moisture dynamics derived from GNSS interferometric reflectometry: A case study for Sutherland, South Africa, GPS Solutions, 20, 641-654, https://doi.org/10.1007/s10291015-0474-0, 2016.

Wan, W., Larson, K. M., Small, E. E., Chew, C. C., and Braun, J. J.: Using geodetic GPS receivers to measure vegetation water content, GPS Solutions, 19, 237-248, https://doi.org/10.1007/s10291-014-0383-7, 2015.

Wigneron, J. P., Chanzy, A., Calvet, J. C., Olioso, A., and Kerr, Y.: Modeling approaches to assimilating $\mathrm{L}$ band passive microwave observations over land surfaces, J. Geophys. Res.-Atmos., 107, 4219, https://doi.org/10.1029/2001JD000958, 2002.

Zavorotny, V. U., Gleason, S., Cardellach, E., and Camps, A.: Tutorial on remote sensing using GNSS bistatic radar of opportunity, IEEE Geoscience and Remote Sensing Magazine, 2, 8-45, https://doi.org/10.1109/MGRS.2014.2374220, 2014.

Zhang, S., Roussel, N., Boniface, K., Ha, M. C., Frappart, F., Darrozes, J., Baup, F., and Calvet, J.-C.: Use of reflected GNSS SNR data to retrieve either soil moisture or vegetation height from a wheat crop, Hydrol. Earth Syst. Sci., 21, 4767-4784, https://doi.org/10.5194/hess-21-4767-2017, 2017. 